\title{
Do-It-Now Building Maintenance Reengineering Project
}

Luis Apodaca, Al Ayotte, John Coffman, Lynnwood Dukes, Sam Jojola, Jim Kadlec, Shannon Letourneau, Robert Matthews, George Paul

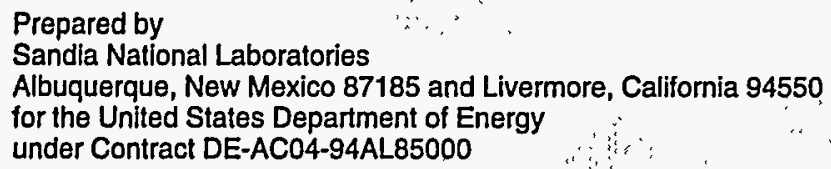

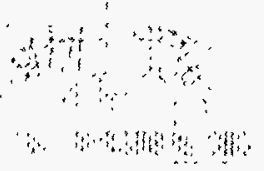
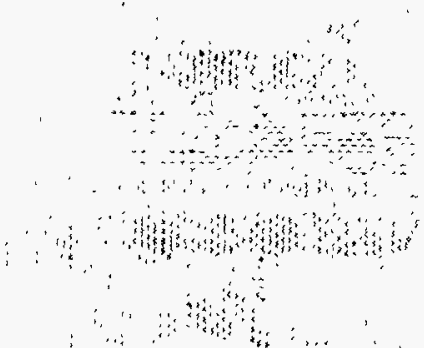
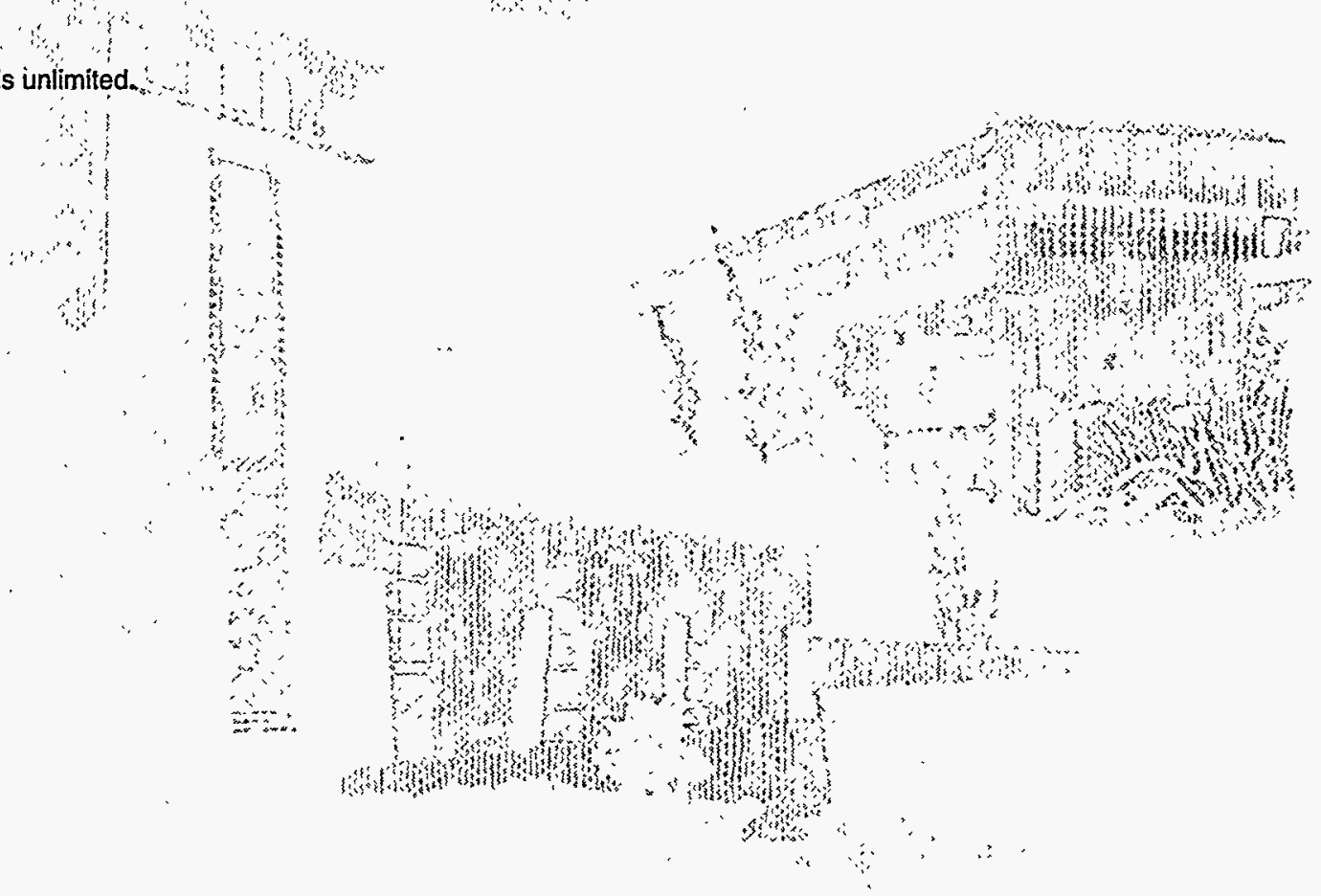
Issued by Sandia National Laboratories, operated for the United States Department of Energy by Sandia Corporation.

NOTICE: This report was prepared as an account of work sponsored by an agency of the United States Government. Neither the United States Government nor any agency thereof, nor any of their employees, nor any of their contractors, subcontractors, or their employees, makes any warranty, express or implied, or assumes any legal liability or responsibility for the accuracy, completeness, or usefulness of any information, apparatus, product, or process disclosed, or represents that its use would not infringe privately owned rights. Reference herein to any specific commercial product, process, or service by trade name, trademark, manufacturer, or otherwise, does not necessarily constitute or imply its endorsement, recommendation,. or favoring by the United States Government, any agency thereof or any of their contractors or subcontractors. The views and opinions expressed herein do not necessarily state or reflect those of the United States Government, any agency thereof or any of their contractors.

Printed in the United States of America. This report has been reproduced directly from the best available copy.

Available to DOE and DOE contractors from

Office of Scientific and Technical Information

PO Box 62

Oak Ridge, TN 37831

Prices available from (615) 576-8401, FTS 626-8401

Available to the public from

National Technical Information Service

US Department of Commerce

5285 Port Royal Rd

Springfield, VA 22161

NTIS price codes

Printed copy: A05

Microfiche copy: A01 
SAND96-1875

Unlimited Release

Printed September 1996

Distribution

Category UC-700

\title{
Do-It-Now. Building Maintenance Reengineering Project
}

Luís Apodaca, Al Ayotte, John Coffman, Lynnwood Dukes, Sam Jojola, Jim Kadlec, Shannon Letourneau, Robert Matthews, George Paul Facilities Operations and Maintenance Center Sandia National Laboratories Albuquerque, NM 87185

\begin{abstract}
The Do-It-Now (DIN) building maintenance system is proposed to reduce the cost of routine building maintenance and repairs and to improve customer satisfaction with maintenance services. DIN uses a team approach to periodically inspect buildings and provide maintenance services on the spot. It emphasizes communications between the customers and the craftspersons performing the work. The system was designed using a reengineering approach that characterized the existing maintenance work control system, analyzed comparable systems in other DOE laboratories, envisioned an ideal system, and proposed a workable, testable system for initial implementation. At each stage, input was solicited from customer representatives and Facilities management to ensure meeting customer requirements with an implementable system.
\end{abstract}




\section{Acknowledgments}

The Do-It-Now building maintenance reengineering team gratefully acknowledges the contributions of a number of Sandians and others to the success of this project. Members of the Steering Committee, Edward D. Graham, Jr., Antonio Chavez, Guy L. Donovan, George I. McLellan, and Edward J. Williams, Jr., were generous with their time and experience in helping make the new system workable. Ad-hoc-. committee members, Dennis Gutierrez, Mike Hurst, and Elizabeth-Scott-Patterson, were invaluable in conveying the customers' point of view. Tom Tomasi and Milton West of DOE/KAO were also instrumental in initiating and-encouraging the reengineering project.

The support and encouragement of Laboratory Services Division Vice President M. Lynn Jones were crucial in the success of this project.

Bernie Mattemore of Lawrence Livermore National Laboratories and Rod Remsburg of Idaho National Engineering Laboratory deserve our thanks for hosting visits to their facilities. They went far beyond the call of duty to provide our comparative analysis teams not only with hospitality, but also with vast quantities of valuable information on their operations.

Finally, the team honors the memory of Nancy Finley, who acted as a customer representative on the ad hoc committee. Her dedication to improving the working lives of her fellow Sandians was obvious and of value to all. The new DIN system shows her influence throughout, and the team hopes it is a fitting memorial. 


\section{DISCLAIMER}

Portions of this document may be illegible in electronic image products. Images are produced from the best available original document. 


\section{DISCLAIMER}

This report was prepared as an account of work sponsored by an agency of the United States Government. Neither the United States Government nor any agency thereof, nor any of their employees, makes any warranty, express or implied, or assumes any legal liability or responsibility for the accuracy, completeness, or usefulness of any information, apparatus, product, or process disclosed, or represents that its use would not infringe privately owned rights. Reference herein to any specific commercial product, process, or service by trade name, trademark, manufacturer, or otherwise does not necessarily constitute or imply its endorsement, recommendation, or favoring by the United States Government or any agency thereof. The views and opinions of authors expressed herein do not necessarily state or refiect those of the United States Government or any agency thereof. 


\section{Table of Contents}

1. Background................................................................................................................

1.1 Do-It-Now a new model for routine building maintenance.................1

1.2 Comparison of Systems DIN and MSR ......................................................3

2. DIN Reengineering Project Scope and Description ...........................................5

2.1 Project description...................................................................................................5

2.2 Project objectives and expected benefits ................................................5

2.3 Project team ..............................................................................................6

2.4 Ad hoc committee ......................................................................................6

2.5 Steering committee.............................................................................................7

2.6 Project schedule and costs................................................................................7

2.7 Reengineering Methodology ...............................................................7

3. New DIN System ......................................................................................................18

3.1 New process description ...................................................................................18

3.2 New system structure.............................................................................24

3.3 Pilot implementation.................................................................................24

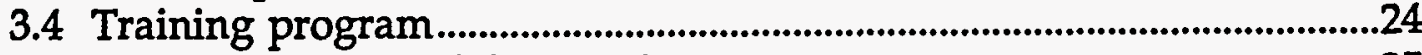

4. Preliminary results and future plans.................................................................25

Appendixes............................................................................................................................. 


\section{Background}

\subsection{Do-It-Now: a new model for routine building maintenance}

Introduction

The Do-It-Now building maintenance system was devised to meet two major goals:

- Reduce costs for routine maintenance

- Improve customer satisfaction with Facilities maintenance services.

As noted in the History section, below, the current maintenance work control system evolved to provide specialized maintenance services for complex building systems and large, integrated maintenance projects. It functions well for this purpose, handling over 25,000 work orders per year. However, customer perception of and satisfaction with maintenance services has as much to do with minor, routine maintenance needs like loose carpet tiles, sticky door frames, etc., as with the more extensive, specialized requirements of building systems. While technical building systems are important, they are often invisible to the building occupants.

A one-year trial of a team-based, proactive approach to routine structural maintenance produced encouraging customer satisfaction results, so the Sandia Operations and Maintenance Center decided to use it as the basis for a new routine building maintenance system. A reengineering project was undertaken to design the new system, expanded in scope (to include other crafts than just structural) and size (to allow more than one team to work at a time). A reengineering process was used to provide a structured approach to analyzing the environment, designing the new system, and estimating its impacts.

\section{History}

Maintenance of Sandia buildings has been an administrative overhead expense, paid for by charges against income of all Sandia organizations. In past years when money flowing in to finance nuclear weapons design and development work was plentiful, Sandia organizations were not over concerned about the money being spent on maintenance. The end of the Cold War and the consequent constraints on Sandia budgets, have led to more concern about costs and more-intense scrutiny of all overhead costs, maintenance included.

Coupled with the pressure on maintenance costs has been increased oversight of maintenance activities. Department of Energy (DOE) Order 4330.4B mandates a new, more stringent conduct of maintenance requirements on all DOE contractors, including Sandia. The effect of these requirements is to further increase overhead costs. Clearly, it is no longer possible for the Facilities Operations and Maintenance Center, which is responsible for building maintenance at Sandia/New Mexico, to conduct business as usual. 
Over the years, Sandia has developed a work control system for building maintenance designed to track large numbers of work requests (over 25,000 per year) and accomplish the requested work as efficiently as possible given the available resources. In this system, building tenants submit Maintenance Service Requests (MSRs) noting the required repairs or services. Submission can be by telephone, electronic message, or paper form. Once the Operation and Maintenance (O\&M) Center receives the request, it is entered into a computer database and assigned to a maintenance planner, who determines the priority of the request, defines requirements for materials and human resources and schedules the corrective work.

In general, the performance of this system has been good. But some concerns .. have prompted the search for new approaches. One is the need to increase , customer satisfaction with routine maintenance services. The current work control system is triggered, by breakdowns or other building deficiencies. Thus, the maintenance system is based in large part on customer dissatisfaction. A second concern comes from the prioritization of work in the MSR system. Since maintenance resources are limited, the most important work is scheduled first, while routine work is done whenever resources are available. This can result in long delays for work that does not involve critical systems or other high-priority items.

A third concern is that the system for entering and fulfilling requests for any Laboratory Services Division service is complex, and customers have little understanding of the system and how to make it meet their requirements. Some maintenance requests can involve a number of maintenance organizations and require the customers to find their own way through a maze of contacts before they can get their jobs done. Making the maintenance process more transparent to customers could make major contributions to improving customer satisfaction and reducing line organization costs related to building maintenance.

In 1994, the O\&M Center began a pilot project to explore a new model for building maintenance. This maintenance model, named Do-It-Now (DIN) shifted responsibility for identifying and reporting building deficiencies from the tenants to maintenance personnel. Periodically, a team of maintenance workers visit each building and, in conjunction with representatives of the tenants, inspect the building for maintenance needs. Once the needs have been identified, the team orders materials and performs all of the repair tasks for which they have the capability. For larger, more time-consuming tasks, or tasks that require special expertise, the team, rather than the tenants, enters MSRs.

Since professional maintenance personnel perform the initial inspection along with the tenants, many preventive maintenance requirements can be identified and potential failures averted. DIN workers can also discuss overall issues of facility condition with the tenants and apply maintenance effort in areas that are most important to the tenants. 
The combination of personal attention and expert surveillance yields high customer satisfaction. Customers can see immediate results from their maintenance requests and can get expert advice on many facilities-related questions. DIN personnel can act as a first point of contact with the Facilities system for complex or non-routine requests, reducing the time and confusion associated with these requests.

DIN also helps reduce maintenance costs in both the short and long terms. Since maintenance personnel stay in a building long enough to perform all routine maintenance activities, fewer maintenance crew trips to the building.are needed than under the current work control system. The DIN work team can procure all maintenance tools and materials for a building at once, for example, and can thus eliminate multiple trips to the warehouse or outside suppliers. This reduces time delays as well as material and personnel costs. Moreover, DIN maintenance actions do not require extensive work planning, saving time and expense. In the long term, periodic inspection and preventive maintenance will serve to extend useful facility life and thereby reduce life-cycle costs.

\section{Customer satisfaction results}

Customer feedback on the DIN maintenance system is solicited through feedback forms and personal contacts with the building coordinators. While trend data are not available due to the limited time during which the feedback form has been used, overall ratings average 4.8 out of $5.0(n=39)$. Unsolicited commendation letters also suggest a high level of customer satisfaction with the DIN concept.

Customers have also been free with their suggestions for improvements. The most frequent suggestions are to increase the scope of services available (adding painting and electrical work, for example) and increase the frequency of DIN visits.

\subsection{Comparison of Systems: DIN and MSR}

\section{Reactive vs. proactive}

The primary difference between the DIN system and the existing MSR system is the mechanism for initiating work. In the MSR system, someone, usually the customer, notices the need for maintenance or repair work and sends the request to the Operations and Maintenance organization via telephone or mail. The request is then logged, verified, and sent to a planner, who determines the materials and personnel required to perform the work. The maintenance craftsmen assigned to the job obtain the required materials and perform the repairs.

In the DIN system, the DIN work team performs their own inspection upon arriving at the building and collects repair and maintenance concerns from the 
building coordinator and other tenants at the same time. Thus; maintenance work can be performed before failures occur or before the condition of the facility deteriorates noticeably. While the process has only been on-going for a year and long-term data are not available, such proactive application of maintenance should result in extended facility life and improved working conditions for building tenants.

Decision making: centralized vs. team-based In the MSR system, all requests are analyzed by planners for their importance and associated risks before being placed in priority order for execution. For major repair actions, this is an important step that maximizes the use of scarce maintenance resources. For routine maintenance and repairs, however, this step can introduce unwarranted delays and increase costs.

In the DIN system, the decisions concerning order in which jobs are done are made by the DIN work team in response to conditions on the job, requirements of the work, and materials availability. For routine matters, this arrangement allows work to be ordered and accomplished efficiently. For major repair or maintenance problems identified during DIN work, the DIN work team submits MSRs for processing through the existing system.

\section{Customer relations: arms length vs. intense}

The most obvious difference between the DIN system and the MSR system is the importance placed on interaction with the occupants of the buildings during the maintenance process. In the MSR system, contact.with the building occupant is limited to taking the request over the telephone and verifying the request before starting work. In the DIN system, occupant contact is virtually continuous throughout the time the DIN work team is in the building. The team makes contact with the building coordinator in advance of beginning work, so that the coordinator can notify the rest of the occupants and collect their maintenance and repair concerns. At the beginning of the building work period, the DIN work team tours the building with the coordinator to locate work areas and identify building-specific hazards and other limitations. During the work period, the DIN work team accepts requests from building occupants for additional maintenance work or, as workload allows, small modifications and maintenance of programmatic equipment. When work is complete, the DIN work team tours the building again with the coordinator to accept completed work and identify work remaining to be done. The goal is to visit each building twice a year.

Customers will therefore be able to maintain long-term communication with the personnel who actually perform the maintenance of their buildings. This nearly continuous communication with the occupants is a large part of the explanation for high customer satisfaction with the DIN system. It is also the reason that DIN work team personnel must be chosen carefully and trained intensively in customer service and communications skills. 


\section{DIN Reengineering Project Scope and Description}

\subsection{Project description}

The DIN reengineering project charter was to plan and implement a system for routine building maintenance and repair based on the Do-It-Now model. Customer satisfaction with the DIN pilot system is high and costs are under control, but the pilot system is limited both in scope and capacity. Only one team was used in the pilot, so the number of buildings and frequency of visits was limited. Moreover, the team members were limited mostly to structural work (walls, ceilings, doors, stairs,floors, etc.), since no electricians, painters, or pipefitters were on the team. The reengineering project was undertaken to expand the scope and capacity of the DIN system. Another objective of the reengineering project was to determine the.actual. costs of building maintenance and attempt to drive them as low as possible.

As part of the Laboratory Services Division reengineering program, the DIN reengineering project was conducted with the oversight of the Division 7000 Vice President and Directors as well as the Division reengineering advisory team. This was done to ensure that the resulting DIN building maintenance system would be compatible with the results of the other reengineering projects. Taken together, the reengineering and process improvement activities will result in profound changes in the way the Laboratory Services Division does business in the future.

The DIN reengineering project is described in detail in the project plan, Appendix 1. The plan uses a standard form used for all Division 7000 reengineering projects. Thus, it not only provides the benefits of any project plan-clarity of objectives, schedule, status tracking, cost controls, etc.-but it also provides for consistency among the Division 7000 projects.

\subsection{Project objectives and expected benefits}

Experience with the DIN processes in the pilot project showed that we could expect high customer satisfaction ratings from an expanded DIN system. The pilot experience also indicated that significant cost savings are also possible, if the expansion is carefully planned and executed. An analysis of cost savings projected to the expanded DIN system is shown in Appendix 2. In particular, benefits of the reengineering project were identified as follows (see Project Profile, Appendix 1):

- Improve customer satisfaction by improving facility aesthetics (subjective measure) and by reducing sources of dissatisfaction with the MSR system

- Increase effectiveness of planners by one FTE by focusing current activities on "true" planning

- Reduce craft hours by two hours per job on average for $10-20 \%$ of all maintenance jobs

- Reduce corrective maintenance activities by $1 \%$ by providing timely preventive maintenance service

- Reduce costs of processing MSRs by $15-20 \%$ by performing corrective maintenance activities through the DIN process

- Reduce time expended by customers to obtain maintenance services by $12.5 \%$. 


\subsection{Project team}

The project team designed the new system and guided its implementation. The team was made up of representatives from Operations and Maintenance and Facilities Development Centers. The team members were chosen to represent engineering disciplines, maintenance planning, supervision, quality.methodologies, and maintenance crafts. The team members were as follows:

- Luís Apodaca, Operations Engineering Department 7816. Maintenance planner and member of implementation team for the new maintenance work control system MAXIMO.

- Al Ayotte, Preventive Maintenance Team 7874-1. Maintenance craftsperson, member of original DIN work team.

- John Coffman, Engineer, Operations and Maintenance Center 7800. Quality processes and liaison with Laboratory Service Division reengineering effort.

- Lynnwood Dukes, Nuclear engineer. Developed work standards, documentation and training materials, consultant on critical systems.

- Sam Jojola, Administrative Support Department 7801. Accounting support, developed cost savings estimates

- Jim Kadlec, Supervisor, Preventive Maintenance Team 7874-1. Team leader and supervisor of the organization in which the new system would be located.

- Shannon Letourneau, now of Nuclear/General Material Storage Team 7618-1. Maintenance craftsperson, designed metrics and developed data baseline.

- Robert Matthews, Facilities Standards and Quality Improvement Department 7907. Team documentation, reengineering process consultation, team facilitation.

- George Paul, Preventive Maintenance Team 7874-1. Maintenance craftsperson, member of original DIN work team

- John Romero, now of ES\&H Assessments Program Office 7314. Engineering consultation, engineering standards, life cycle cost analysis.

Consultants

- Jeff Lowenthal, reengineering methodology

- Bruce Hawkinson, communications strategy and methods

\subsection{Ad hoc committee}

The project team was assisted by a panel of representatives of customer organizations. From the outset, customer perspective was deemed necessary for development of the DIN system. Formal meetings were held to solicit the ad hoc committee's input on requirements, and the committee was consulted periodically to review the proposed system as it developed. Members of this ad hoc committee were as follows:

- Dennis Gutierrez (9000)

- Mike Hurst (1000)

- Nancy Finley (6000)

- Elizabeth Scott-Patterson (5000) 


\subsection{Steering committee}

The steering committee was made up of managers of cognizant Facilities organizations and a representative of a customer organization. This committee provided the reengineering team with help. in two major areas. First, they provided the benefit of their experience in and with Facilities organizations in the design of the new system. Second, they reviewed the proposed new system for its ability to be implemented in the current. Facilities and Sandia environments. Members of the steering committee were as follows:

- Edward D. Graham, Jr., Director, Facilities Operations and Maintenance Center 7800

- Antonio Chavez, Manager, Facilities Operations and Maintenance Department II 7872

- Guy L. Donovan, Fusion Accelerator Department 1236

- George I. McLellan, Customer Services and Space Management Office 7312; Zone Manager, Area I East.

- Edward J. Williams, Jr., Manager, Facilities Shared Systems Department 7874.

2.6 Project schedule and costs

Project Start-7/29/95

Project Completion-4/1/96

Project cost- $\$ 246,000$. Detail is as follows:

\begin{tabular}{|c|c|c|}
\hline DIVISION 7000 REENGINEERING FUNDS & $\begin{array}{l}\text { FY9S SPEND } \\
\text { PLAN }\end{array}$ & $\begin{array}{c}\text { FY96 SPEND } \\
\text { PLAN }\end{array}$ \\
\hline Line 1: FTEs (from indirect chargers) & 0.47 & 0.91 \\
\hline Line 2: FTEs converted to $\$$ (from Line 1) & 60,833 & 118,959 \\
\hline Line 3: FTEs from direct chargers) & 0 & 0 \\
\hline Line 4: FTEs converted to \$ (from Line 3) & 0 & 200 \\
\hline Line 5: DC (Direct Charges) & 5,270 & 33,062 \\
\hline Line 6: Service Center Charges & 0 & 3,074 \\
\hline Possible LPR Funded (Line $4+$ Line 5) & 5,270 & 24,262 \\
\hline Total FTE (Line $1+$ Line 3) & 0.47 & .91 \\
\hline Total Cost (Line $2+$ Line $4+$ Line $5+$ Line 6$)$ & 66,103 & 179,557 \\
\hline
\end{tabular}

\subsection{Reengineering Methodology}

The reengineering methodology employed for this project is summarized in the model Division 7000 Reengineering Project Plan (see Appendix 1) as supplemented by the Process Modeling and Innovation model developed by Performance Solutions International, Ltd. In this model, the project team characterizes the current business system with respect to customer requirements and performance; conceptualizes new, ideal processes comprising a new business system; tests the new processes through pilot implementation; and plans for full-scale implementation of the new system. 
Treating the reengineering effort as a project with a written project plan provides the benefits of clear definition of project objectives and resources at the outset. During the project, the plan provides a reference to guide team operations.

The Process Modeling and Innovation method divides the reengineering project into a series of steps provides a list of questions, the answers to which document the reengineering project as it proceeds (see-Appendix 3). The strength of this-approach is that the checklist makes it unlikely that important components of the reengineering methodology will be overlooked. It also provides a permanent record of the team's activity for future reference.

\section{Step 1-Identify Current Business Process}

The Do-It-Now (DIN) pilot program showed the possibilities for decreased costs, increased customer satisfaction, and increased efficiency in routine building maintenance as compared with the MSR system. In view of the probability of declining maintenance budgets, the efficiency and cost improvements are attractive. In addition, customer satisfaction improvements will be necessary to ensure the survival of the Sandia Operations and Maintenance organization.

Unlike many Facilities processes, the primary customers of this process are individual employees and other tenants of Sandia buildings. In addition, the tenant organizations receive information concerning the condition of their buildings and recommendations for major repairs. The major outputs of the process are as follows:

- Safe, productive, and pleasant work areas for tenants

- Corrective action on deficiencies for tenants, zone manager, and building operators

- Small, customer-funded modifications

- Customer-funded maintenance services for programmatic equipment

- Inspection data for other maintenance organizations

- Recommendations for other repairs (MSRs) for zone managers and building tenants.

Since most of the repairs are requested by the customers, customers will be able to determine whether the repairs have been made. They may be less able to determine if preventive maintenance meets their requirements. Customers can communicate their satisfaction with the process via a point-of-service response card the DIN team leaves with the building coordinator at the conclusion of the DIN maintenance visit. No similar vehicle for customer feedback exists for the MSR system.

\section{Step 2-Determine Scope of Reengineering Project}

An important contributor to the success of any project is to clearly identify the scope before beginning the project. This helps the team determine throughout the project what work is necessary to accomplish in order to achieve the project goals. The elements of scope include requirements (as set by the project sponsor), 
benefits to be derived from the project, drawbacks to be mitigated in the system design, primary customers and the outputs they receive, suppliers and their inputs to the process, boundaries of the process (where it starts and ends), and schedule constraints.

Sponsor's requirements on the reengineering project were to delight Facilities customers by supplying high-quality services to Sandia and to constrain overhead costs as much as possible. These requirements are related. In order to save costs, the Operations and Maintenance Center must reorganize and change the ways it does business. To do this, it should make incremental efforts now to restructure and achieve the resulting cost savings instead of tackling the whole cost problem. There should be numerous parallel efforts designed to complement each other. Customer appreciation of maintenance must increase, and space chargeback costs must be seen by the customer as worth the cost. To accomplish this, maintenance must be performed more cost-effectively with reduced hours and with increased customer contact and communication. This would result in reduced cost, faster response, better customer relations, and consistently good work quality.

Benefits to the customers of this project would include lower cost and greater efficiency of maintenance. Improved worker satisfaction would also result from having well trained work crews, documented processes and metrics, increased worker flexibility, and increased knowledge of the work process. Additional benefits accruing to the Operations and Maintenance Center include less scheduled backlog of work and reduced management overhead.

Drawbacks. Along with the potential benefits, there are also potential drawbacks that must be considered in the redesign effort. These include the possibility that the current, rigid culture could prevent change; a potential lack of union support for the process; and possible lack of Sandia Labor Relations buy-in. In designing the work processes, it must be kept in mind that not all personnel fit into the DIN model of working and that not all types of work fit the process. Therefore consideration must be given to possible redundancy of efforts and turf issues. Of particular concern is the question of whether there will be enough work to keep the process participants busy. Management issues include the possible lack of management support and need for particular qualifications for management leading the process. Finally, there is the possibility of increased costs for some types of work, since the DIN work teams are likely to correct some conditions that customers would not have called in.

Primary customers of the building maintenance process were identified as the building residents and their representatives, including organizational facilities coordinators (OFCs), ES\&H coordinators, and building coordinators. Other customer groups include other maintenance organizations (who receive work orders from DIN personnel), zone managers (who manage spaces between buildings and therefore can request maintenance services from DIN work 
teams), DOE (as building owner), and the Facilities Engineering Standards Program (who receive suggestions for engineering design improvements).

Outputs of the maintenance process include safe, productive, and pleasant work areas for the building occupants, inspection inputs and work orders to other maintenance organizations, and compliance with DOE orders and other regulations for the work space.

Inputs to the DIN maintenance system include MSRs, the building DIN schedule, asbestos reports, DIN building work plans, and maintenance materials (from the Sandia warehouse and vendors).

Boundaries. Unlike a "textbook" reengineering project, the DIN reengineering project began with the new processes, already in place in pilot form. A work team had been operating for several months testing the DIN concept in actual practice. Therefore, the task of the DIN reengineering project was to design a system whereby the DIN concept could be expanded to perform a wider variety of maintenance tasks on a larger number of buildings and a more frequent schedule than the pilot process allows.

In addition, since the customers' satisfaction with the DIN process was high, expanding the scope of services delivered through the DIN system was deemed appropriate and valuable. The problem for this part of the reengineering project was to determine the types of additional services well suited to delivery through DIN and design the system to accommodate this expansion.

Schedule. A schedule Gantt chart for the project is shown in the project plan, . Appendix 1.

\section{Step 3-Map and Analyze the Current Process}

In order to define the enhancements and redesign necessary to develop the new system, the existing DIN pilot system was analyzed in detail. This analysis was documented extensively, since an agreed-on current state was required to provide a basis for design decisions for the new system.

Figure 1 is a flowchart of the existing DIN pilot process. Figure 2 is an integrated flow diagram (IFD) of the existing process. While the flowchart shows the flow of work between the various participants of the process, the IFD shows the communications paths between the participants and the information that flows over them. 


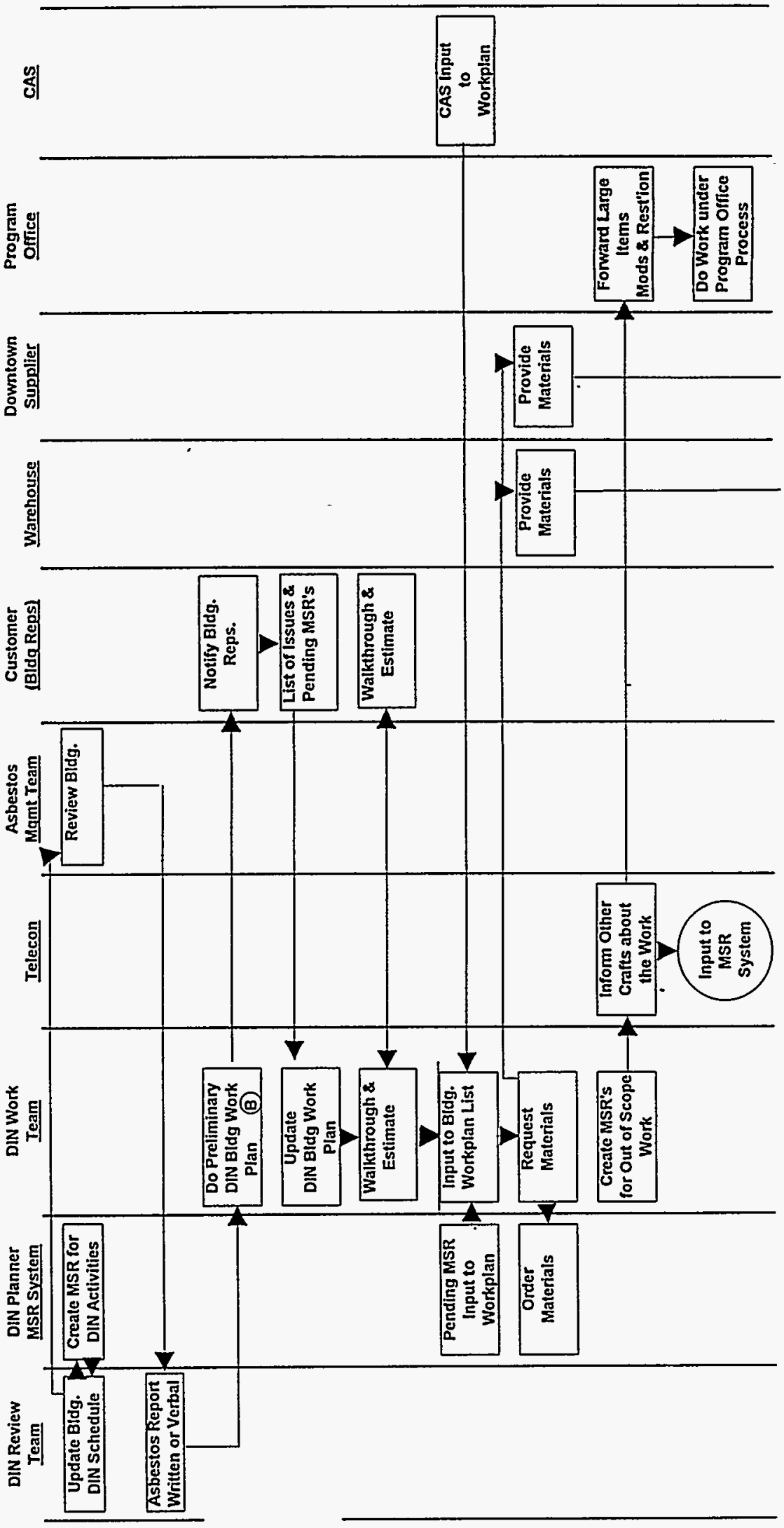

Figure 1. Existing DIN Process Flow Chart (Sheet 1 of 2) 
ํํำ

톨힌

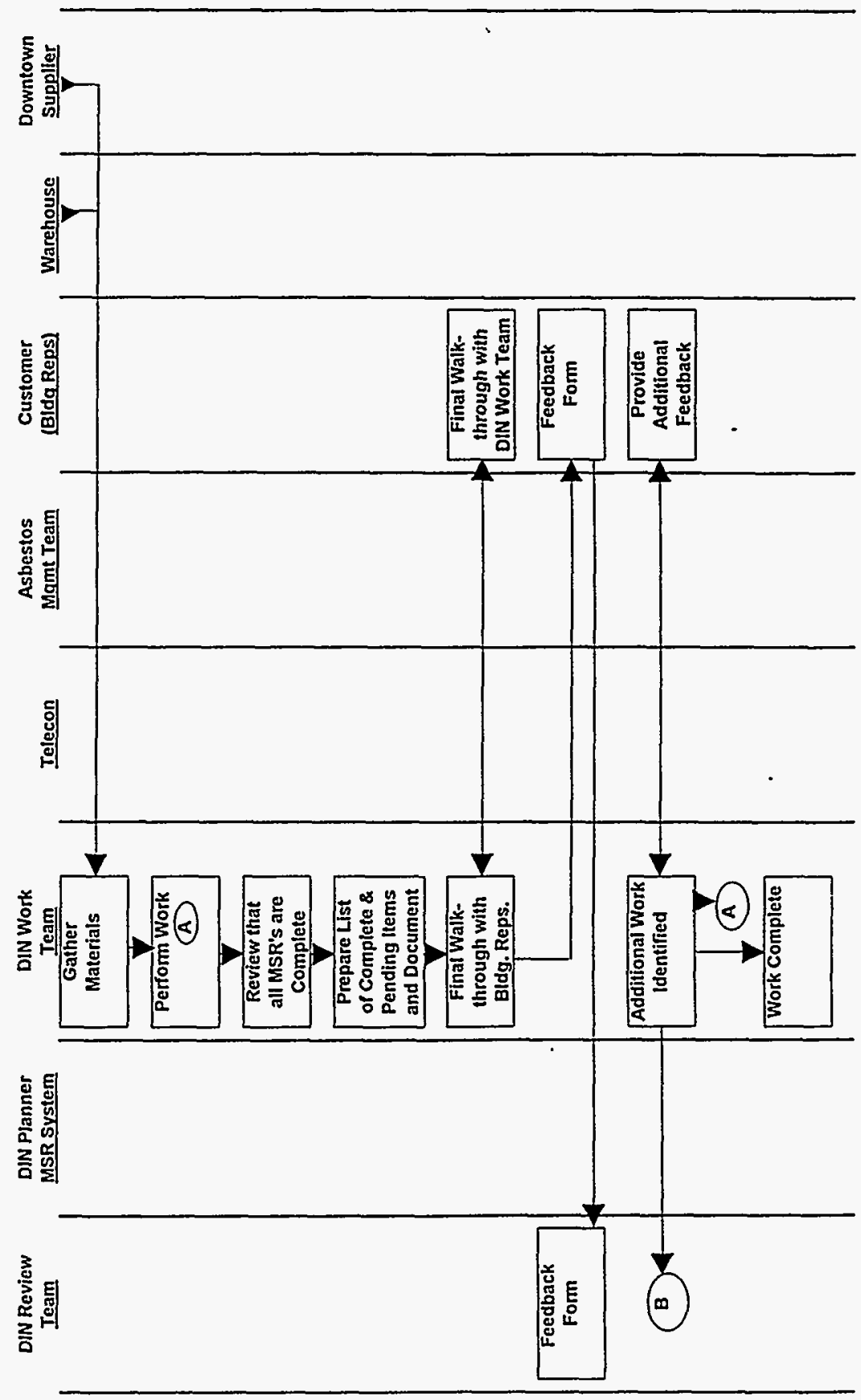

Figure 1. Existing DIN Process Flow Chart (Sheet 2 of 2) 

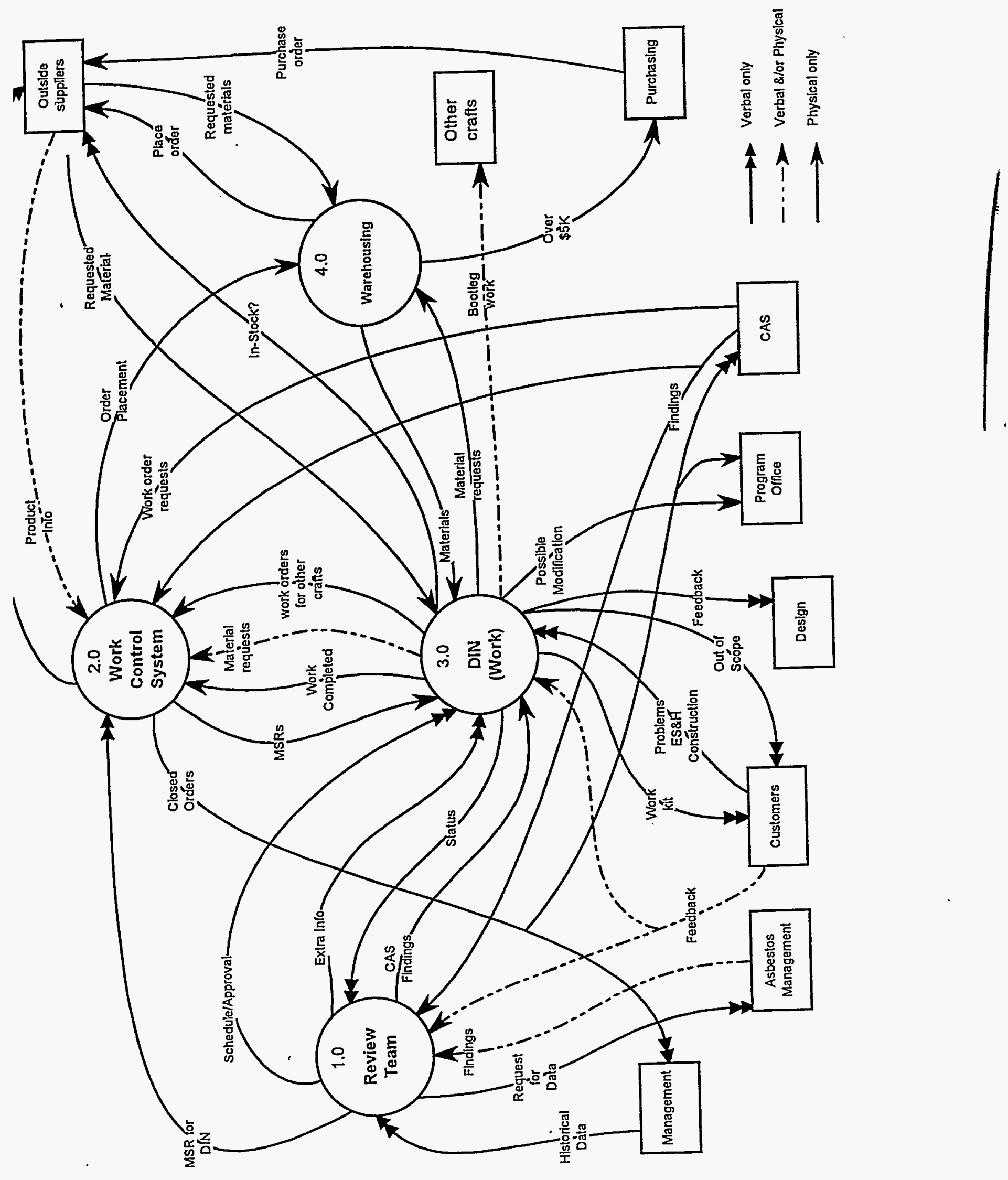

Figure 2. Existing DIN Process Integrated Flow Diagram 


\section{Comparative Analysis Process and Results}

A comparative analysis study was conducted to determine how other DOE laboratories have used team-based, proactive maintenance approaches and what lessons they have learned in doing so. Initial contacts through the Energy Facilities Contractors Operating Group (EFCOG) indicated that Lawrence Livermore National Laboratories (LLNL) and Idaho National Engineering Laboratory (INEL) have developed team-based approaches to maintenance.and ... that they were willing to share information with Sandia concerning them. The following are summaries of the important findings from the study. For detailed reports of the findings refer to Appendix 4.

Lawrence Livermore National Laboratory. The LLNL approach to team-based maintenance service is called "windowing." This concept focuses on preventive maintenance (PM), since it was one area customers identified as needing most improvement. Under the windowing system, each building at the Laboratory (with the exception of some small, temporary buildings and mobile offices) is scheduled for a two- to five-day period, or window, of PM twice a year. If preventive maintenance workers find deficiencies, they can call on the resources of the central Plant Engineering shops to perform corrective maintenance during the window.

Customer satisfaction with windowing is high, since maintenance-related downtime has been greatly reduced. In general, craft workers are also enthusiastic about the windowing process due to job enhancement, improved working conditions, and opportunities for technical support.

While the windowing process is more extensive than the proposed DIN processes, it is instructive for the design of the DIN system. First, the payoffs in customer and employee satisfaction were encouraging for the DIN reengineering team, since they match Sandia's experience with the DIN pilot. Second, LLNL's experience indicates that these benefits scale with increasing the scope and intensity of the system. Direct cost savings in the LLNL experience derive mostly from reductions in facility down-time due to maintenance. Improvements in preventive maintenance should also result in cost savings, although these savings will only become apparent after several years of operations.

Idaho National Engineering Laboratory. Crafts workers at INEL suggested a new concept of work organization, which was accepted by management. The concept is multi-craft crews assigned to facilities (with flexibility to meet extraordinary demands). Each facility has single point of contact with the central Facilities, Utilities and Maintenance (FUM) group. FUM maintains special shops to handle the central area and "body shop" support for other areas.

Maintenance requests for high-rigor facilities go to a core team for the program functional area. The core team includes safety, fire protection, radiation protection, industrial hygiene, quality, engineering, and NEPA support 
personnel. They are dedicated to reviewing and approving maintenance work orders. A maintenance foreman sits on the core team to give the crafts perspective. The core team likes to use their foreman's crew, but they can assign work to any crew on priority basis. The core teams greatly reduce the amount of time required to get proper approvals and permits for maintenance work at highrigor facilities.

In the recent past, INEL has had a team-based system for maintenance of lowrigor buildings called Rapid Maintenance Response (RMR). The multi-craft RMR teams were limited to jobs that took less than 4 hours, and they did not do hazardous work. Therefore, their work was mostly routine maintenance. They looked through one building a week to identify maintenance needs. The teams felt like they owned the buildings they worked on. This encouraged close contact with building occupants. Unfortunately, budget cuts caused INEL to drop the RMR concept and assign the workers to area teams or to the Central Facilities Area shops.

The INEL experience with team-based routine maintenance can serve as a caution for Sandia. Measurement of the costs and benefits of the DIN should be taken continuously both to justify continued existence of the system and to ensure efficiency and continuous improvement of services.

\section{Step 4-Create the Ideal Process}

Experience with the DIN process through the pilot period convinced management and the reengineering team that further improvements in building maintenance could result from expanding the capacity of the process both in scope (the types of maintenance performed) and amount of work performed in a given time period. To accomplish this, a new process was developed to preserve the team-based maintenance activities and customer contact of the pilot process while expanding the expertise and human resources available to the teams and revamping the "back-office" activities that support the maintenance workers in the field.

The first step in designing the new process was to list the services to be provided. The current services list is in Section 3.1, below.

The next step was to determine how the new and expanded services could be provided. Matrixed personnel assignments could address requirements for additional workers, and new management alignments (zone management, Physical Subsite Management, etc.) could be put in place. A serious obstacle to putting plans into place was the changing management situation of the Operations and Maintenance Center. Reorganization and downsizing were ongoing while the team was-designing the new system. Since the management situation is so fluid, the process was designed to operate under a variety of reporting arrangements. 
The process that resulted from the design effort are described more fully in Chapter 3. The processes are characterized by a high degree of autonomy and responsibility on the part of the DIN workers. Teams have great flexibility in determining how their work is to be done and, in the case of customer-funded work, what work is to be done. As a result, there has been great emphasis on documenting the processes in detail and training team members in the use of the processes (see Section 3.4). There has also been considerable effort devoted towards developing a set of metrics that the teams can use to monitor and improve the processes as they gain experience with them. The metrics are described more fully in Section 4.2.

\section{Step 5-Test the New Process}

Since the DIN prototype has been in operation for about a year, no formal pilot test of the new system was considered. However, rollout of the new DIN system will be accompanied by implementation of the process metrics noted above and a continuing process improvement methodology.

When the new system is implemented, the DIN work teams, planners, and managers will meet on a regular basis to review metrics information, analyze the system, and propose improvements. Since the meetings will be frequent (weekly at the beginning), a variety of small improvement projects can be undertaken quickly and analyzed according to their impact on the metrics. The team anticipates that such projects will be common in the first few months of operation as the workers become familiar with the system and how it interacts with the actual work environment.

A new customer feedback form (Figure 3 ) has been designed to collect customer satisfaction information, along with customer comments regarding what went wrong, what went right, and what should be done to improve the system.

After approximately six months' experience with the process, the team will have enough experience with the new system to propose enhancements such as further scope expansion, etc.

\section{Step 6-Implement the New Process}

As noted above, the implementation and testing phases of this project are simultaneous. Much of the effort devoted to designing the new DIN system was directed towards making the process analysis and improvement straight-forward and effective. 


\section{Satisfaction Ratings}

For each of the following questions, please circle the number that corresponds to your opinion. Write your comments in the spaces provided or on a separate sheet, if you need more space.

1. How satisfied were you with the timeliness of DIN service (did the team show up on time and complete their work quickly)?

Very

Dissatisfied 1

2

Neutral

Comments:

2. How satisfied were you with the effectiveness of the DIN work (did the repairs fix the problems and did any modifications meet your requirements)? Very

Dissatisfied

1

Comments:

3. How satisfied were you with the craftsmanship of the DIN workers?

Very

Dissatisfied

1

Comments:
Neutral

3
2

Neutral

3

Very

Satisfied

45

Satisfied

45
Very

Satisfied

5

4. How satisfied were you with the courtesy with which the DIN workers treated you?

Very

Dissatisfied

1

Comments:

Neutral

3

Very

5. How satisfied were you with the DIN process overall?

Dissatisfied

1

Comments:
2
Neutral
3

\section{Additional Comments}

6. What part of the DIN process did you like the most?

7. What part of the DIN process did you like the least?

8. What additional services should DIN offer in the future?

Figure 3. Customer Feedback Form 


\section{New DIN System}

\subsection{New process description}

Building Maintenance Services: The new DIN process was designed to provide the following building maintenance services:

Structural

The ideal scope of structural products will include existing DIN products:

- Wall repairs

- Floor Coverings and base molding repairs and replacement

- Stair landings inspection and repairs

- Carpet repairs

- Door repairs and replacement

- Ceiling tiles/grid systems repair and replacement

- Restroom fixture repairs

- Sprinkler escutcheons installation

- Masonry repair and replacement

- Cover plates installation

- Computer floor tile leveling / repair

- Standard office furniture minor repairs (related to safety)

- Caulking

- Glass/Glazing Repair

- Signs installation and repair

- Outside grounds cleanup and maintenance

Electrical

- Plates and covers installation

- Junction boxes inspection

- Abandoned conduit and circuits removal

- Emergency lighting relocation

- Electrical safety repairs

- Loose monuments repair

- Counterfeit circuit breaker inspection

- Grounding and lightning protection checks

- Static-free rooms inspection, testing, and repair

Painting

- Hole repairs in stucco, block, sheetrock, metal, and doors

- Base molding painting

- Glass and glazing repairs and small replacement

- Exterior painting - curbs, parking lots, crosswalks, cabs, walls, fascias, soffits, windows

- Interior painting-non-skid stairs, landings, handrails, chair rails

- Furniture repairs

- Specialty painting

- Taping and texturing

- Water stains cleaning

- Floors sealing 


\section{Miscellaneous}

- Evaporative cooler stands

- Roof inspection and small repairs

- Handrails, guardrails, stairs, and landings inspection and repair

- Seals/Bearings

- Systems furniture repair

- Sinks, Water closets, Fountains PM and repair

- Moving furniture (in support other craft) and small moves

- Stair/Landings/ramp painting

- Drain maintenance

- Bike racks, picnic tables, roof ladders, and other outside equipment checkup and repair

- Painting (interior and exterior) general touch-up

- Lamps and ballasts repair and replacement

- Install receptacles

- Install lighting

- Relocate receptacles

Customer-funded work: In addition to standard building maintenance work, the DIN work teams would be able to assist customers by performing small modifications and programmatic work that is paid for by the customer organization. Jobs of this type would be accepted by the DIN work team only if they could be completed without adversely affecting the overall DIN schedule. Examples of this work are as follows:

Small Modifications. To be accepted, the total estimated budget must not exceed $\$ 4,000$ and the estimated labor content must be no more than 16 manhours. Examples of this kind of work include installing book shelves, hanging liquid writing boards, installing or moving electrical receptacles, rearranging systems furniture, etc.

Programmatic Maintenance. This term refers to maintenance of customer equipment and property other than facilities. Programmatic maintenance would be funded by the customers. The decision as to whether the DIN work team accepts any given job would depend on the particular skills of the work team members and the ability of the team to complete the requested work without adversely affecting the overall DIN schedule. Examples of this work include the following:

- Equipment PM as requested and paid for by customers

- Slings and hoists checking

- Flammable Cabinet leveling

- Other.

Process flow: The overall process flow for the DIN building maintenance is shown in Figure 4. Flow charts for small modifications and programmatic maintenance processes are shown in Figure 5. 
DO-IT-NOW (DIN) PROCESS PRESENT PROCESS FLOWCHART

\begin{tabular}{|c|c|c|c|c|c|c|c|c|c|}
\hline \multirow{13}{*}{ 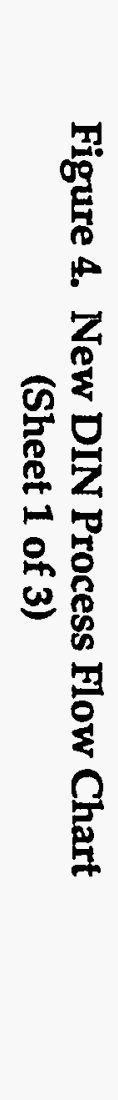 } & \multirow{4}{*}{ 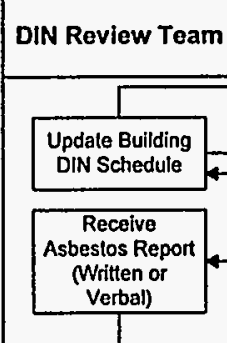 } & $\begin{array}{l}\text { DIN Planner MSR } \\
\text { System }\end{array}$ & \multirow[t]{3}{*}{ DIN Work Team } & $\begin{array}{l}\text { Asbestos Mgmt. } \\
\text { Team }\end{array}$ & $\begin{array}{c}\text { Customer } \\
\text { (Bldg. Reps.) }\end{array}$ & Warehouse & $\begin{array}{l}\text { Downtown } \\
\text { Supplier }\end{array}$ & Program Office & CAS \\
\hline & & \begin{tabular}{|l} 
Croatit Work \\
Orderf for II \\
Adivilies by
\end{tabular} & & $\frac{17}{\text { Review Bulding }}$ & & & & & \\
\hline & & & & & & & & & \\
\hline & & & Preparo & & & & & & \\
\hline & & & 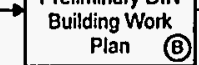 & & & & & & \\
\hline & & & $\frac{d}{0 \text { Update DIN }}$ & & $\frac{f}{\text { List Issus and }}$ & & & & \\
\hline & & & Plan & & & & & & \\
\hline & & & $\left|\begin{array}{|c}\text { Walkhthough and } \\
\text { Estisnate }\end{array}\right|$ & & 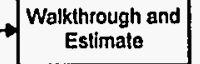 & & & & \\
\hline & & $\begin{array}{l}\text { Input Pending } \\
\text { MSS Lo Work }\end{array}$ & $\sqrt{\text { Inpout to Buldting }}$ & & & & & & 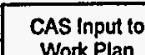 \\
\hline & & & 1 & & & . & & & \\
\hline & & Order Materals & Materast & & & + & $\square$ & & \\
\hline & & Input or Creale & 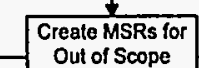 & & & & & 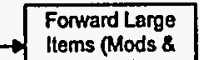 & \\
\hline & & & & & & & & & \\
\hline
\end{tabular}


DO-IT-NOW (DIN) PROCESS PRESENT PROCESS FLOWCHART (Continued)

$\stackrel{N}{N}$

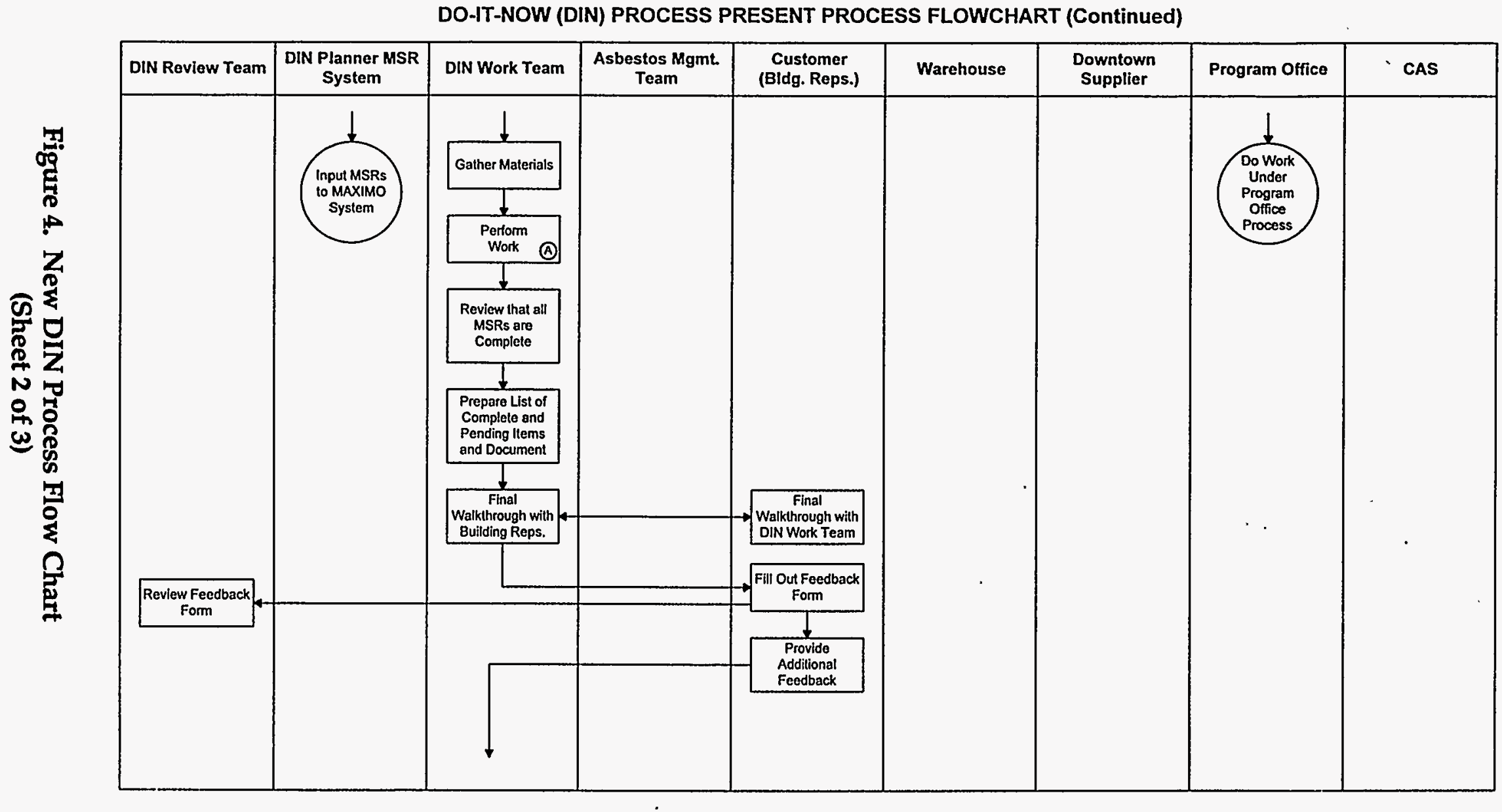




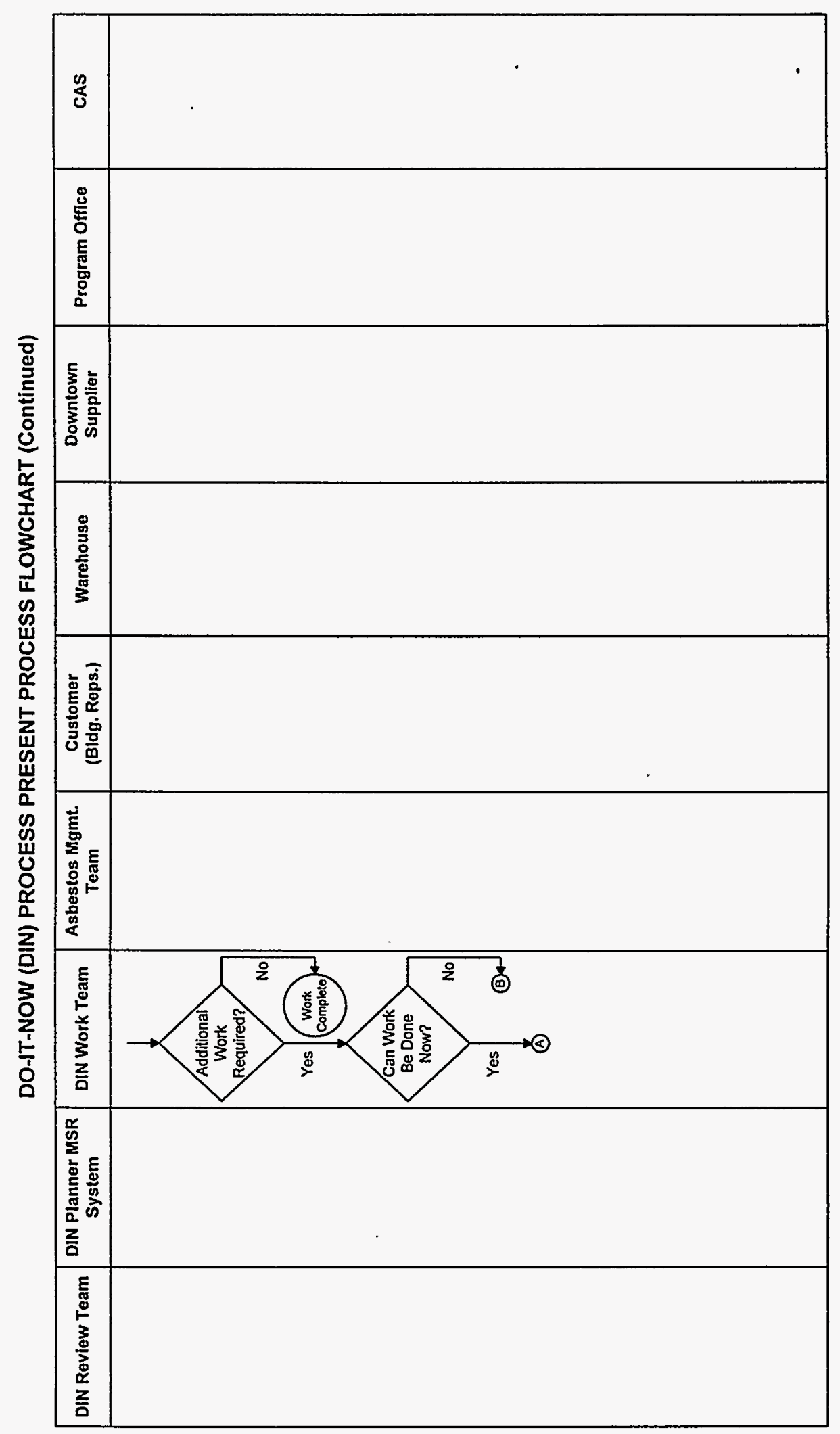

Figure 4. New DIN Process Flow Chart

(Sheet 3 of 3) 


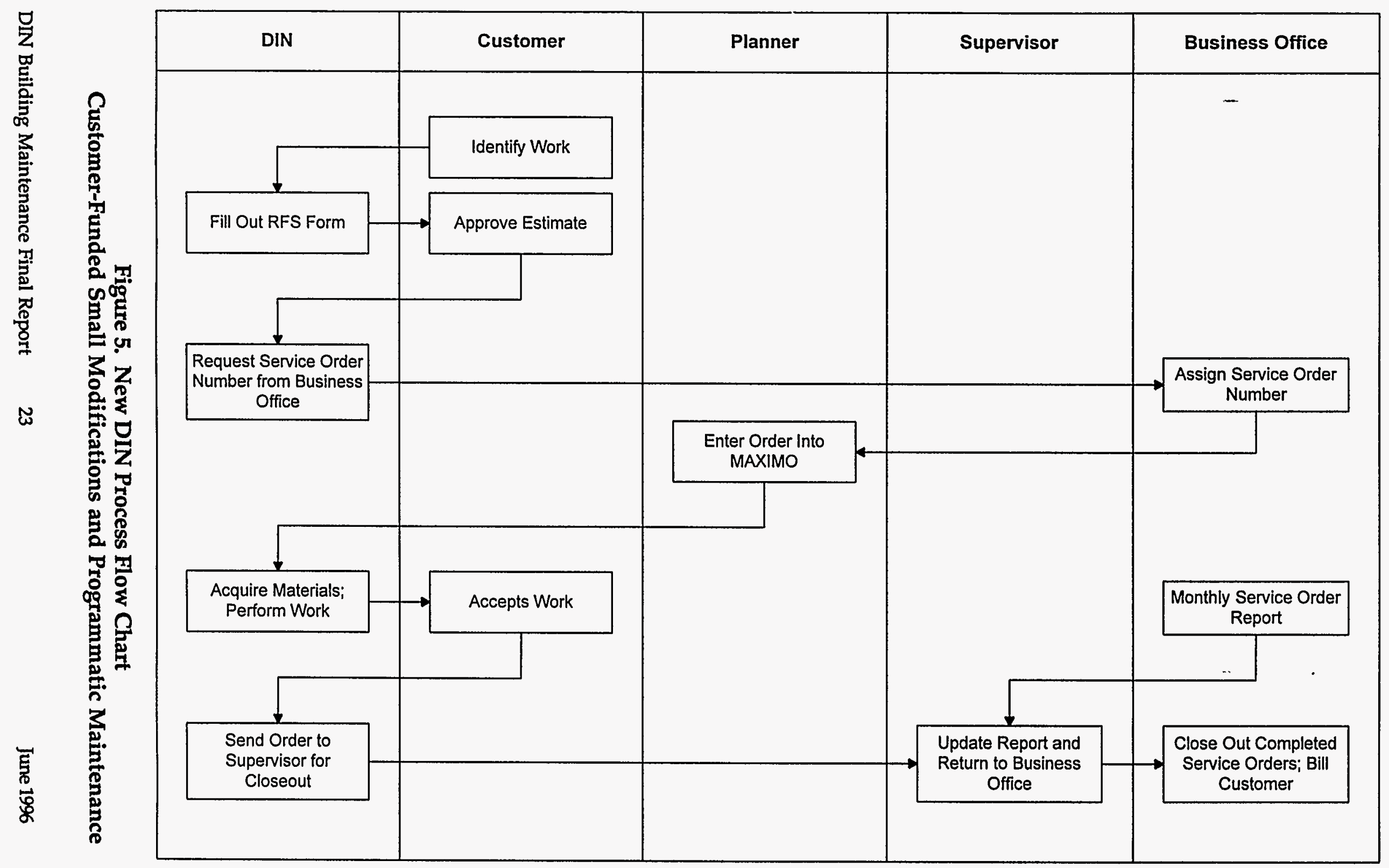




\subsection{New system structure}

The DIN work teams report administratively to Preventive Maintenance Team 7874-1. Two DIN teams are currently deployed, each consisting of two structural maintenance technicians. A lamper will be available to both teams for emergency relamping. Two painters, one electrician, and one pipefitter are available to the teams as needed. They continue to report administratively to other Operations and Maintenance Center departments, but have a matrix relationship to the Preventive Maintenance Team.

In addition to the work teams, the Preventive Maintenance Team includes a planner dedicated to DIN for materials ordering and other maintenance planning functions.

\subsection{Pilot implementation}

Implementation will begin as soon as approval is obtained from the Steering Committee and resource commitments have been received. The target date for beginning of implementation is April 1, 1996.

\subsection{Training program}

The primary goal of the DIN training program is to enable workers who have not previously been involved with the DIN process to work effectively and efficiently in the new DIN environment. To develop the details of this goal, the DIN process documentation was analyzed to determine the activities that DIN work team members would be expected to perform. Note that in this analysis, the activities that would normally be expected as part of the DIN workers trades (structural, mechanical, electrical, etc.) are not included, since satisfactory performance of these activities is part of the selection criteria for team members.

Examination of the activities shows requirements for the following categories of skills. These categories constitute the instructional goals for the DIN team member training program

- Customer contact and communications-including determining customer requirements, handling special customer requests, and dealing with customer complaints

- Process and procedures-including DIN administrative procedures, customer-funded work requests, etc.

- Metrics and data gathering-identifying required measurements, collecting data, analyzing data for process improvement, and presenting measurement information to decision makers

- Process improvement methodology-including process analysis, identifying opportunities for improvement, implementing process changes, and determining the effect of improvements

- Effective meetings skills-including meetings for information sharing, decision making, and process improvement

- Computer skills-as required to implement DIN business systems 


\section{Preliminary results and future plans}

Preliminary results will be reported as soon as they become available after implementation. Reports will include metrics and customer satisfaction results.

Part of the customer feedback form is devoted to collecting information on customer desires for new and expanded services. Therefore, planning for future enhancements to the DIN system will begin as soon as reliable information is obtained. 


\section{Appendixes}

1. Reengineering Project Plan ..............................................................................................3

2. Cost Savings Analysis........................................................................................11

3. Reengineering Questions and Answers .................................................................21

4. Comparative Analysis Reports...................................................................................63 


\section{Appendix 1 Reengineering Project Plan}

\section{DIVISION 7000 REENGINEERING MANAGE PHYSICAL SITE PROJECT PROFILE SHEET, FORM 1}

\begin{tabular}{|c|c|}
\hline ROJECT NAME Do-lt-Now Building Mainte & DATE_August 16. 1995 \\
\hline & HAT? \\
\hline $\begin{array}{l}\text { PROJECT DESCRIPTION(1) } \\
\text { Plan and implement a process for general } \\
\text { building maintenance and repair based on the } \\
\text { Do-It-Now model. }\end{array}$ & $\begin{array}{l}\text { RELATED PROJECTS (2) } \\
\text { Physical Sub-Site Management (PSSM) } \\
\text { Alan Spencer, team leader)) } \\
\text { Customer-Funded Facilities Modifications } \\
\text { Kathleen McCann (Procurement), Dave Bailey } \\
\text { (Facilities) }\end{array}$ \\
\hline $\begin{array}{l}\text { PROCESS PRIMARY CUSTOMER(S) (11) } \\
\text { Residents of the buildings } \\
\text { Zone manager } \\
\text { Other maintenance groups } \\
\end{array}$ & \\
\hline & HY? \\
\hline $\begin{array}{l}\text { PROJECT PURPOSEOBJECTIVES ( } 3 \text { ) } \\
\text { Improve customer satisfaction by } \\
\text { improving facility aesthetics (subjective } \\
\text { reducing dissatisfaction with MSR system } \\
\text { Increase effectiveness of planners by } 1 \text { FTE by } \\
\text { Reduce craft hours by two hours per job on ave } \\
\text { Reduce corrective maintenance activities by } 1 \% \\
\text { service } \\
\text { Reduce costs of processing MSRs by } 20-25 \% \text { b } \\
\text { through the DIN process } \\
\text { Reduce time expended by customers to obtain m }\end{array}$ & $\begin{array}{l}\text { feasure) } \\
\text { focusing current activities on true planning } \\
\text { age for } 20-25 \% \text { of all maintenance jobs } \\
\text { by providing timely preventive maintenance } \\
\text { y performing corrective maintenance activities } \\
\text { aintenance services by } 12.5 \%\end{array}$ \\
\hline $\begin{array}{l}\text { PROCESS PERFORMANCE MEASURE(S) - (12) } \\
\text { Customer satisfaction survey } \\
\text { Craft hours per service request } \\
\text { Number of MSRs } \\
\text { Hours of planners time devoted to other than t }\end{array}$ & ue planning \\
\hline $\begin{array}{l}\text { PROCESS CURRENT/BASELINE PERFORMANCE (13) } \\
\text { Customer satisfaction survey ( } 5 \text { categories, } \\
\text { results between } 3.5 \text { and } 4.1 \text { on a scale of } 5 \text { ) } \\
\text { Other than true planning hours }=12 \text { hour/day } \\
\text { ( } 7 \text { planners, DIN-type jobs in current MSR } \\
\text { system) } \\
\text { Craft hours }=4.8 \text { per MSR (comparable to DIN } \\
\text { work) } \\
\text { Number of MSRs }=29,177 \text { (FY94) }\end{array}$ & $\begin{array}{l}\text { PROCESS TARGET/FUTURE PERFORMANCE (14) } \\
\text { Customer satisfaction survey results } 4.5 \text { or } \\
\text { above for each category ( }+.5 \text { to } 1.0) \\
\text { Other than true planning hours }=3 \text { hour/day } \\
\text { ( }-9 \text { hours) } \\
\text { Craft hours }=2.8 \text { per MSR }(-2 \text { hours) } \\
\text { Number of MSRs }=22,000 \text { per year }(-7,000)\end{array}$ \\
\hline & HO? \\
\hline $\begin{array}{ll}\text { PROJECT TEAM MEMBERS } & (4) \\
\text { Luís Apodaca } & \text { Shannon Letourneau } \\
\text { John Coffman } & \text { Robert Matthews } \\
\text { Lynnwood Dukes } & \text { John Romero } \\
\text { Sam Jojola } & \\
\end{array}$ & 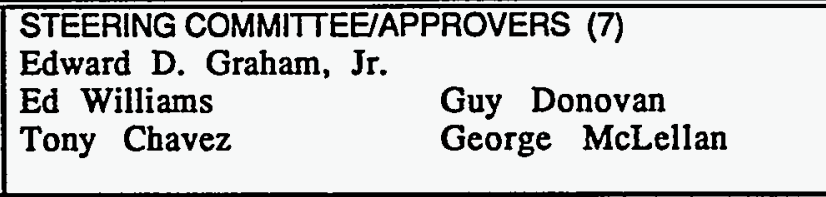 \\
\hline $\begin{array}{l}\text { PROJECT LEADER (5) } \\
\text { Jim Kadlec }\end{array}$ & $\begin{array}{l}\text { PROJECT SPONSOR (8) } \\
\text { Edward D. Graham, Jr. }\end{array}$ \\
\hline & \\
\hline $\begin{array}{l}\text { PROJECT TARGET START (6) } \\
7 / 29 / 95\end{array}$ & $\begin{array}{l}\text { PROJECT TA } \\
12 / 15 / 95\end{array}$ \\
\hline
\end{tabular}


EXPECTED BENEFITS FROM IMPROVED PROCESS (15)

Savings:

Planning costs direct involvement

Planner efficiency due to DIN items not being in MSR process

Craft hour/job

Time processing MSRs

Customer and Facilities time preparing MSRs

Transportation costs

Life cycle costs due to increased preventive maintenance

Supervisor overhead

Material acquisition

Safety hazards

ESTIMATED TOTAL PROJECT COST: (10)

$\$ 395,000$

ESTIMATED BENEFIT (\$) FROM IMPROVED PROCESS:

Greater than $\$ 1$ million in first year (2.5 ROI) 


\title{
DIVISION 7000 REENGINEERING MANAGE PHYSICAL SITE ACTIVITIES DESCRIPTION, FORM 2
}

\author{
PROJECT NAME Do-It-Now Bailding Maintenance Pmcess REV NO. _ DATE_August 14. 1925
}

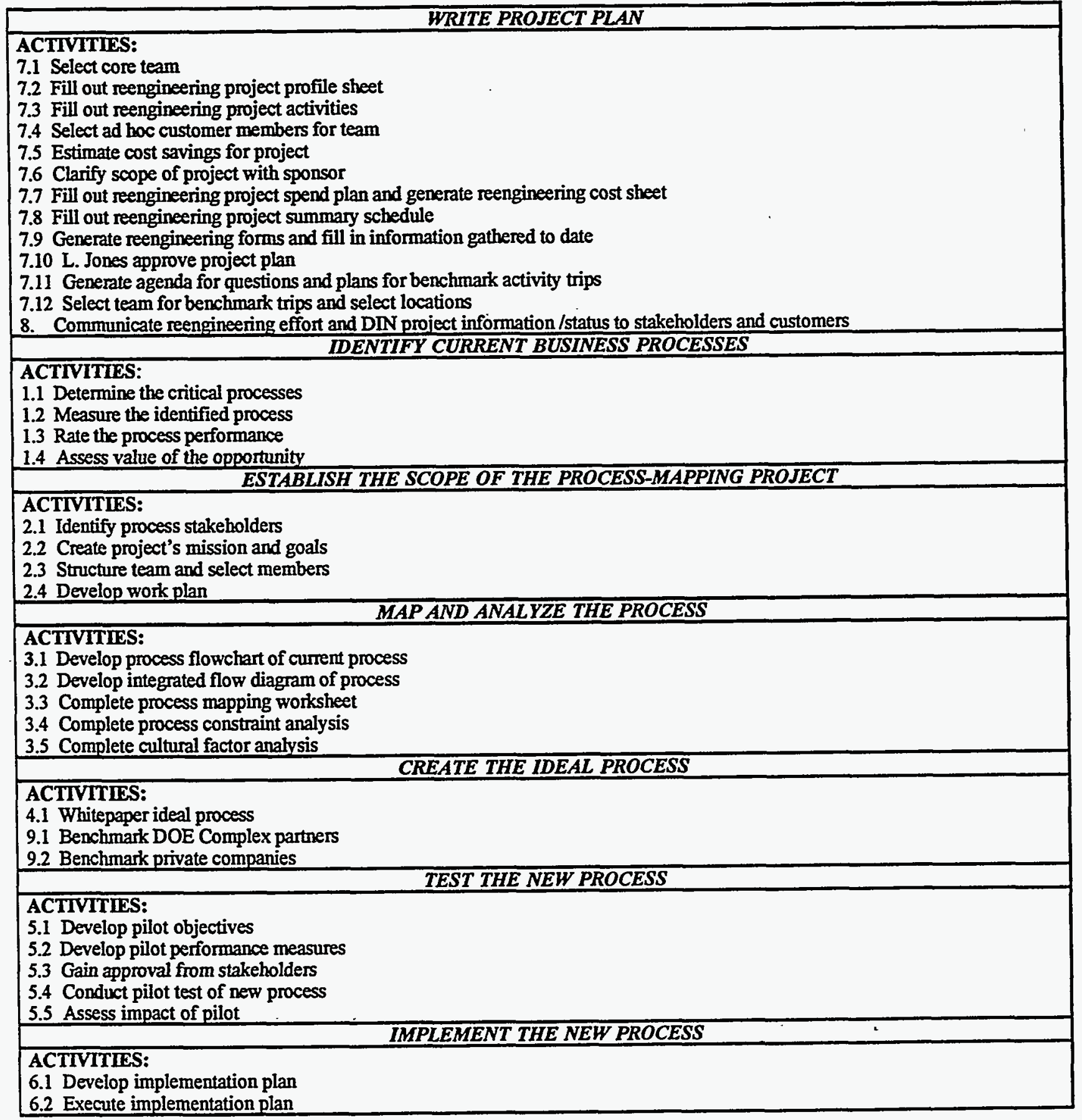

DIN Building Maintenance Final Report A-5 June 1996 


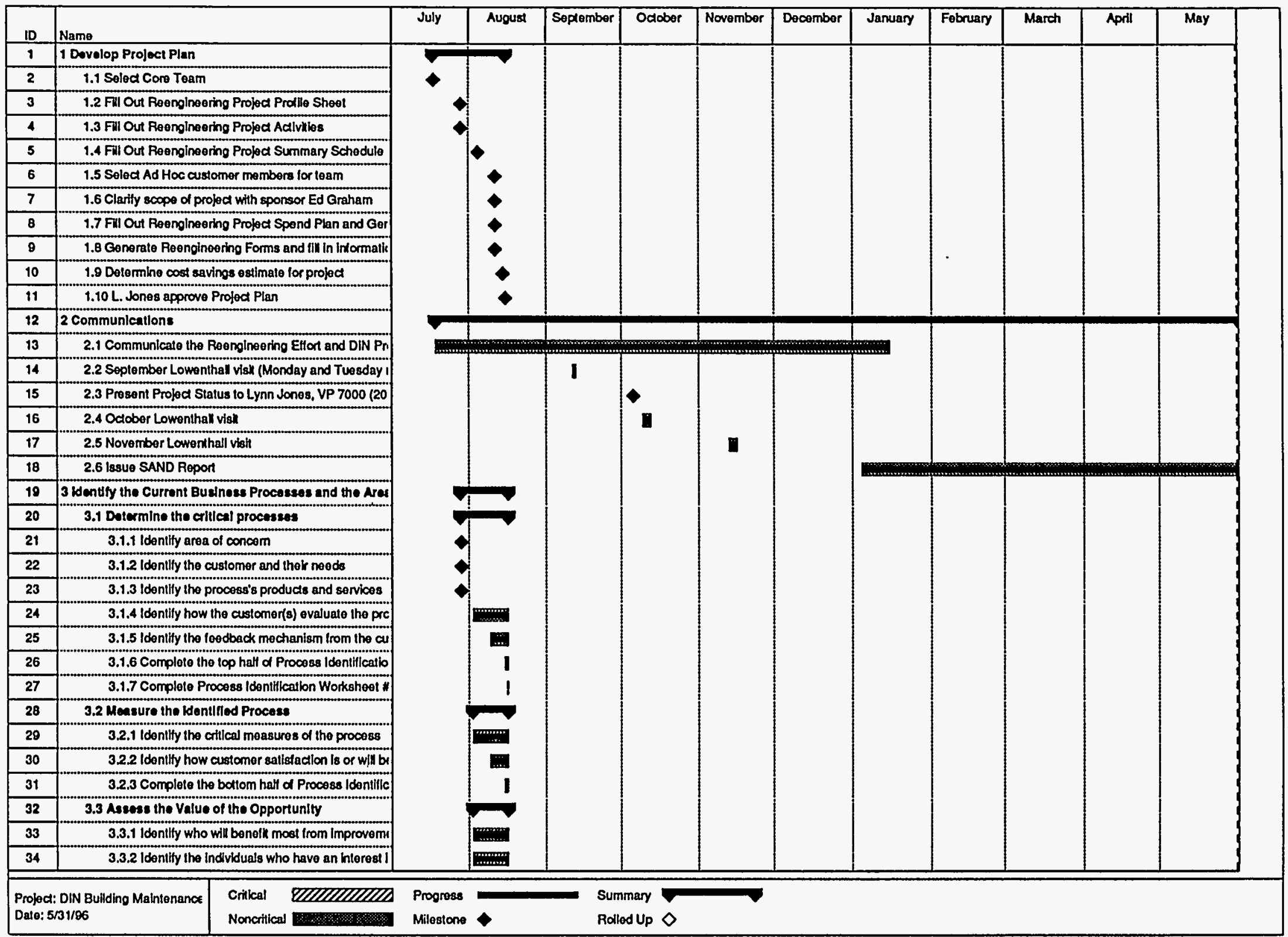




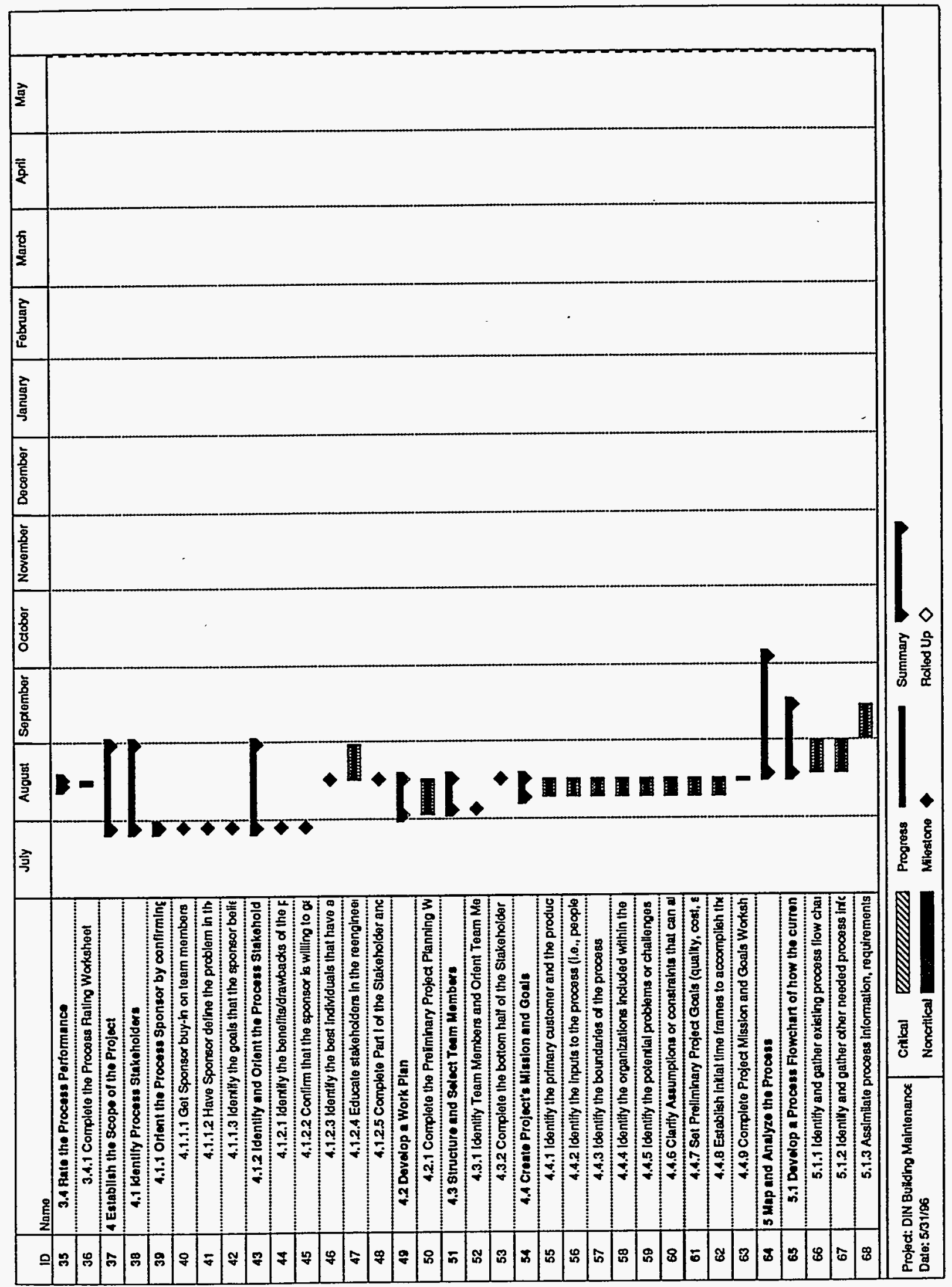




\begin{tabular}{|c|c|c|c|c|c|c|c|c|c|c|c|c|c|}
\hline 10 & \multicolumn{2}{|l|}{ Name } & July & August & Soptomber & Oclober & November & Decomber & January & Fobruary & March & April & May \\
\hline 69 & \multicolumn{2}{|c|}{ 5.1.4 Develop a Procoses Flow Chart loo the DIN por } & & & D & & & & & & & & \\
\hline 70 & \multirow{2}{*}{\multicolumn{2}{|c|}{ 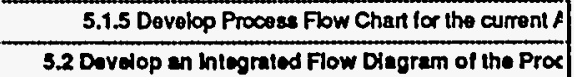 }} & & & & & & & & & & & \\
\hline 71 & & & & & & & & & & & & & \\
\hline$\overline{72}$ & \multicolumn{2}{|c|}{ 5.2.1 Determine extemal onthios, primary actwitios } & & $\mathbf{m}$ & & & & & & & & & \\
\hline 73 & \multirow{2}{*}{\multicolumn{2}{|c|}{$\begin{array}{l}5.2 .2 \text { Develop an Inlograled Flow Dlagram, revlow, } \\
3.3 \text { Complete the Process Mapping Workehoet }\end{array}$}} & & & & & & & & & & & \\
\hline 74 & & & & & & & & & & & & & \\
\hline 75 & \multirow{2}{*}{\multicolumn{2}{|c|}{5.3 .1 Enter procoses hpus, outpus, tarpets, astor }} & & & & & & & & & & & \\
\hline 76 & \multirow{2}{*}{\multicolumn{2}{|c|}{$\frac{5.3 .2 \text { Develop Process Mapping Disgrams utilizing }}{5.3 .3 \text { Intrograte Procoss Flow Dlagram Intormation }}$}} & & & $\operatorname{man}_{1}$ & & & & & & & & \\
\hline 77 & & & & & $\mathbf{0}$ & & & & & & & & \\
\hline 78 & \multicolumn{2}{|c|}{3.4 Benchmark Eftort } & & & & & & & & & & & \\
\hline 79 & \multicolumn{2}{|c|}{ 5.A.1 DOE Complox Partnor(s) } & & & & & & & & & & & \\
\hline 80 & \multicolumn{2}{|c|}{ 5.4.1.1 Chooee Benchmarking Patnoers } & & : & & & & & & & & & \\
\hline 81 & \multicolumn{2}{|c|}{$\begin{array}{l}5.4 .1 .2 \text { Got Aproament of partlcipalion } \\
\text {. }\end{array}$} & & & & & & & & & & & \\
\hline 82 & \multicolumn{2}{|c|}{ 5.4.1.3 Writoup Checkllst } & & & & & & & & & & & \\
\hline 83 & \multicolumn{2}{|c|}{$\begin{array}{l}\text { 5.4.1.4 Trtp Viatiation } \\
\text {. }\end{array}$} & & & .......... & & & & & & & & \\
\hline 84 & \multicolumn{2}{|c|}{5.4 .1 .5 Ganerato Trip Roport } & & & & I & & & & & & & \\
\hline 85 & \multirow{2}{*}{\multicolumn{2}{|c|}{ 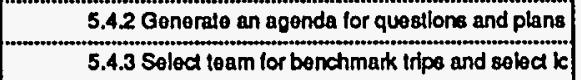 }} & & $\bullet$ & & & & & & & & & \\
\hline 86 & & & & $\bullet$ & & & & & & & & & \\
\hline 87 & \multicolumn{2}{|c|}{3.5 Complote - Process Constralnt Analysle } & & & & & & & & & & & \\
\hline 88 & \multicolumn{2}{|c|}{5.5 .1 Survey hadviduals in the aurent procosess to $\mathrm{k}$} & & & & & & & & & & & \\
\hline 89 & \multirow{2}{*}{\multicolumn{2}{|c|}{$\begin{array}{l}3.6 \text { Complate a Cultural Fuctor Analy yle } \\
5.6 .1 \text { Survey individuals in the current procoss to on }\end{array}$}} & & & & & & & & & & & \\
\hline 80 & & & & & B...…1 & & & & & & & & \\
\hline 91 & \multicolumn{2}{|c|}{6 Croatio the vioal Process } & & & & & & & & & & & \\
\hline 92 & \multicolumn{2}{|c|}{ 6.1 Whilitepuper the Ideel Process } & & & & & & & & & & & \\
\hline 93 & \multirow{2}{*}{\multicolumn{2}{|c|}{ 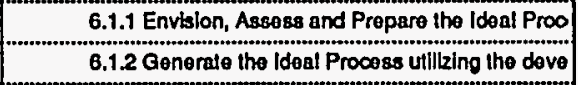 }} & & & & & & & & & & & \\
\hline 04 & & & & & & $m$ & & & & & & & \\
\hline 85 & \multicolumn{2}{|c|}{6.2 Compare the Actual Procoss to the low } & & & & 1 & & & & & & & \\
\hline 96 & \multicolumn{2}{|c|}{ 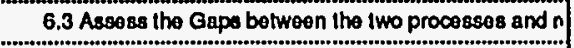 } & & & & $\mathbf{I}$ & & & & & & & \\
\hline 97 & \multicolumn{2}{|c|}{7 Tost tho Now Process: } & & & & & & & & & & & \\
\hline 98 & 7.1 Dovelop Pllot ob] & Ellves & & & & & & & & & & & \\
\hline$\infty$ & 7.1.1 Manpower a & roval for DIN pllot and porsone & & & & & & & & & man & & \\
\hline 100 & 7.1 .2 Complete PI & Planning Worksheet \#1 & & & & 1 & & & & & & & \\
\hline 101 & 7.2 Conduct $\mathrm{PllotT}$ & it of the Now Procoses & & & & & & & & & & & \\
\hline 102 & 7.2 .1 Dovelop an & thon Plan tor the pibt & & & & 】 & & & & & & & \\
\hline $\begin{array}{l}\text { Proloc } \\
\text { Data: }\end{array}$ & $\begin{array}{l}: \text { DIN Buld dho Maintonanc } \\
\text { i31/86 }\end{array}$ & 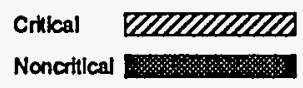 & $\begin{array}{l}\text { Progross } \\
\text { Mllostone }\end{array}$ & & & nary $\bar{c}$ & & & & & & & \\
\hline
\end{tabular}




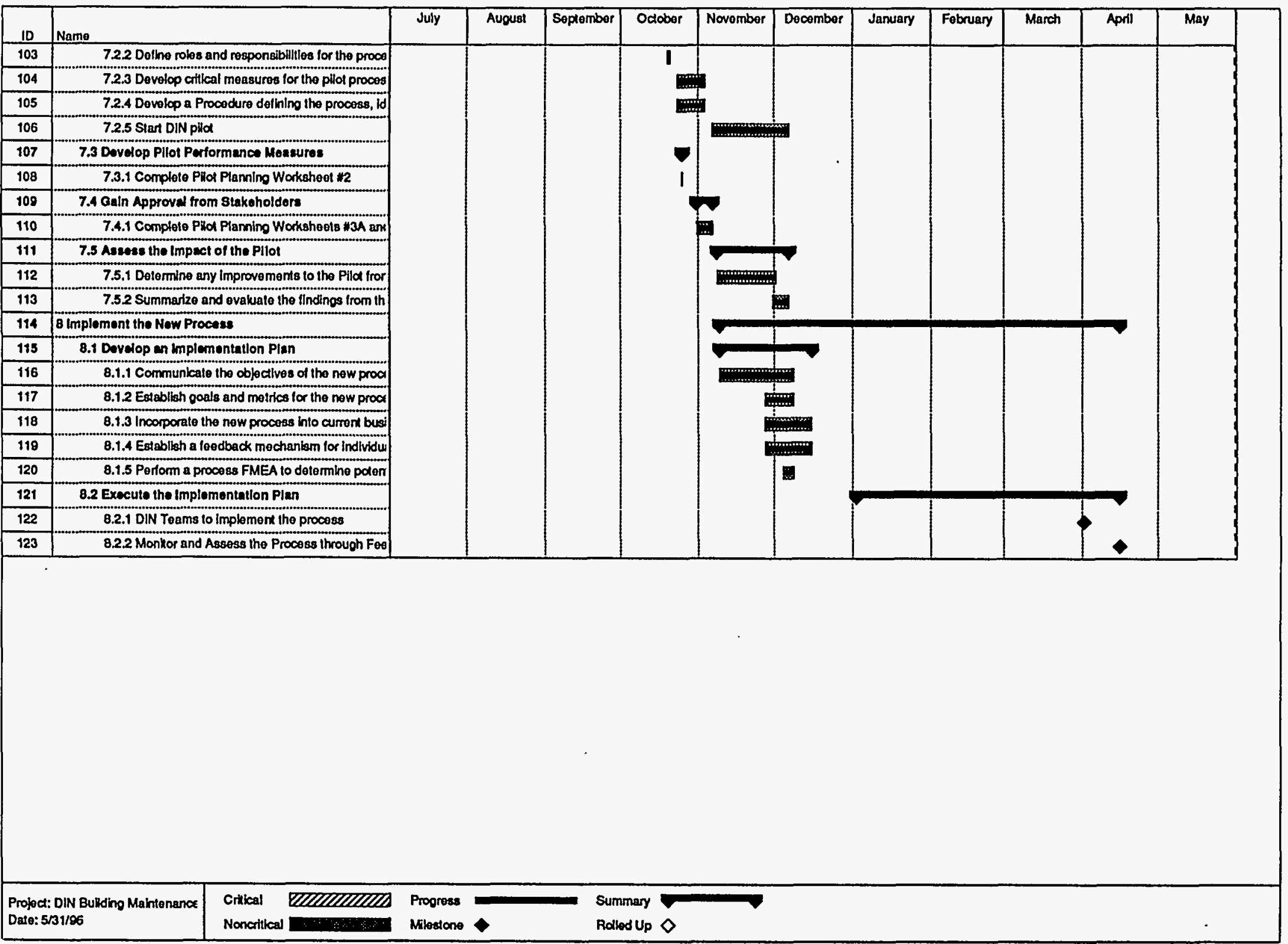




\section{Appendix 2 \\ Cost Savings Analysis}

COST SAVINGS SUMMARY

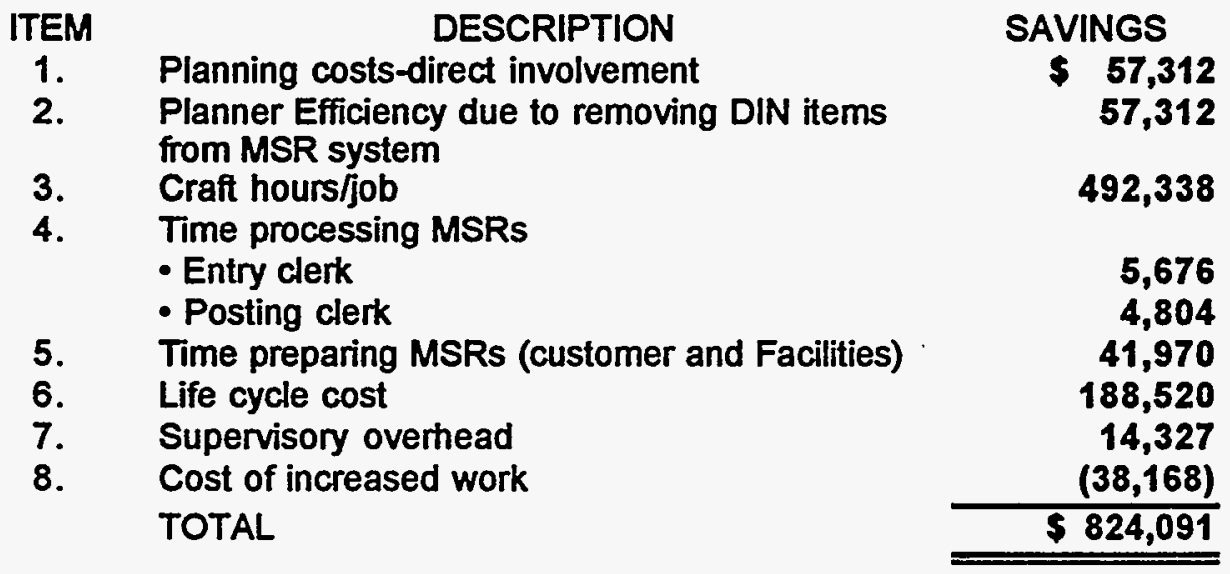

\section{PLANNING COST DIRECT INVOLVEMENT}

Planner's who spend time on DIN type MSRs:

$\begin{array}{ll}7809-1 & \text { Orlando Griego } \\ 7812-3 & \text { Rick Pierson } \\ 7812-5 & \text { James Dotson } \\ 7814-1 & \text { Lyle Golightly } \\ 7814-2 & \text { Lyle Golightly } \\ 7814-4 & \text { F. Molina } \\ 7814-4 & \text { F. Molina } \\ 7818-1 & \text { Bemard Alexander } \\ 7818-2 & \text { G. Garcia } \\ 7818-2 & \text { G. Garcia }\end{array}$

Carpenter S-1

Pipe fitting/Plumbing $M-2$

Pipe fitting/Plumbing $M-2$

Pipe fitting/Plumbing $M-2$

Pipe fitting/Plumbing $\mathbf{M - 2}$

Carpenter S-1

Service Mechanic S-4

Pipe fitting/Plumbing $M-2$

Carpenter S-1

Field Painting P-1

Hours per

Day

0.5

1.0

1.0

0.5

0.5

1.5

1.0

2.0

1.5

2.5

Conservative Estimate Adjustment - Not all DIN type

MSRs will go away as a result of DIN. - $15 \%$

Planner Base hourly rate $=\$ 18.48$

Incremented $=$ Base $\times 1.55$

28.64

Indirect $=$ Incremented $\times .6$

Center Support $=$ Incremented $\times .455$

13.03

TOTAL

58.86 
NOTE:

DINable MSRs $(3,038 / 7,084) \quad 0.43$

CONSERVATIVE COST SAVINGS:

Hours per day $x$ Loaded Planners Hourly Rate $x$ \# of Work Day/Yr.

$10.2 \times 58.86 \times 222 \times .43$

$\$ 57,311.51$




\section{PLANNER EFFICIENCY DUE TO REMOVAL OF DIN ITEMS FROM MSR SYSTEM}

Planner efficiency will increase by the time saved not having to do DIN type MSRS

Planner's who spend time on DIN type MSRs (See Item \# 1 for supporting detail):

$\begin{array}{ll}7809-1 & \text { Orlando Griego } \\ 7812-3 & \text { Rick Pierson } \\ 7812-5 & \text { James Dotson } \\ 7814-1 & \text { Lyle Golightly } \\ 7814-2 & \text { Lyle Golightly } \\ 7814-4 & \text { F. Molina } \\ 7814-4 & \text { F. Molina } \\ 7818-1 & \text { Bemard Alexander } \\ 7818-2 & \text { G. Garcia } \\ 7818-2 & \text { G. Garcia }\end{array}$

Carpenter S-1

Hours per

Day

Pipe fitting/Plumbing $M-2$

Pipe fitting/Plumbing $M-2$

Pipe fitting/Plumbing M-2

Pipe fitting/Plumbing $M-2$

Carpenter S-1

0.5

Service Mechanic S-4

1.0

1.0

0.5

Pipe fitting/Plumbing $\mathbf{M - 2}$

0.5

Carpenter S-1

1.5

1.0

Field Painting P-1

2.0

1.5

$\frac{2.5}{12.0}$

Conservative Estimate Adjustment - Not all DIN type

MSRs will go away as a result of DIN. $-15 \%$

Planner Base hourly rate $=\$ 18.48$

Incremented $=$ Base $\times 1.55$

Indirect $=$ Incremented $\times .6$

Center Support $=$ Incremented $\times .455$

NOTE:

58.86

Ratio of Original Cost Estimate MSRs used to actual

DINable MSRs $(3,038 / 7,084)$

CONSERVATIVE COST SAVINGS:

Hours per day $x$ Loaded Planners Hourly Rate $x$ \# of Work Day/Yr.

$10.2 \times 58.86 \times 222 \times .43$

$\$ 57,311.51$

The same amount saved as a result of planners not having to do DIN type

MSRs can now be devoted to "true planning" (See ltem \# 1 for supporting detail). 


\section{CRAFT HOURS/JOB}

BASE SALARY =

INCREMENTED

INDIRECT

CENTER

TOTAL

Total DINable items*

Average hours per DIN item

Average hours when item DINed Hours saved per project

DINable items $x$ Hours saved $\times$ Hourly rate

Savings $=3,038 \times 3 \times 54.02$
16.96

26.29

15.77

11.96

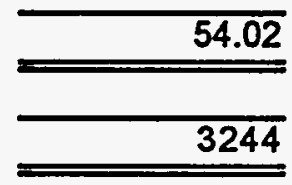

4.8

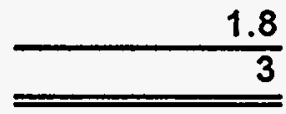

*Number of work orders that qualify under the DIN criteria.

$\begin{array}{lcccc}\begin{array}{c}\text { Type of Work } \\ \text { Structural }\end{array} & \text { FY93 } & \text { FY94 } & \text { FY95 } & \text { Average } \\ \quad \text { (S1\&S4 } & 2131 & 2596 & 2131 & 2286 \\ \quad \begin{array}{l}\text { less than } 50 \\ \text { manhours/job) }\end{array} & & & & \\ \begin{array}{l}\text { Mechanical } \\ \text { (M2 plumbing, }\end{array} & 825 & 1214 & 1085 & 1041 \\ \quad \begin{array}{l}\text { less than 10 man- } \\ \text { hours/job) }\end{array} & & & & \\ \begin{array}{l}\text { Painting } \\ \text { (P1, less than 24 }\end{array} & 571 & 420 & 322 & 438 \\ \text { man-hours/job) } & & & & \end{array}$

Assuming that DIN can do $85 \%$ of the available, qualifying structural and mechanical work and $95 \%$ of the qualifying painting work, the total number of equivalent MSRs done by DIN in the first year would be

$\begin{array}{lrl}\text { Structural } & 1943 & (85 \% \text { of } 2286) \\ \text { Mechanical } & 885 & (85 \% \text { of } 1041) \\ \text { Painting } & 416 & (95 \% \text { of } 438) \\ \text { Total } & 3244 & \end{array}$

\section{TIME PROCESSING MSRS}




\section{ES\&H VERIFICATION}

At the present time there is no charge for this service

Savings

ENTRY CLFRK

It takes an average of $2.5 \mathrm{~min}$. per MSR to enter into the AMM System

DINable MSRs $=3,038$

Tier 3 clerk hourly rate $=\$ 14.03$

Incremented $=$ Base $\times 1.55$

Indirect $=$ Incremented $\times \mathbf{. 6}$

Center Support $=$ Incremented $\mathbf{x}$ .455

TOTAL

$2.5 \times 3,038=7,595$

$7,595 / 60=127$

Savings Entry Clerk $127 \times 44.69=$

\section{POSTING CLERK}

It takes an average on 2 minutes per time card to post time to work orders

DINable MSRs $=3,038$

Total Craftsmen $=139$

NOTE:

Total Time Cards $=139 \times 222=30,858$

DINable $\%=3,038 / 29,065=10.45 \%$ 


\section{TIME PREPARING MSRS (CUSTOMER \& FACILITIES)}

We estimated that it takes approximately 10 minutes to prepare MSRs

Total DINable MSRs $=3,038$

FY 95 Spending Plan Company Wide:

Unloaded

$\$ 438,220,966$

Fringe - Loaded

Fully Loaded

$574,410,831$

$1,278,012,299$

Total FTEs

$8, \mathbf{5 7 6 . 3}$

Total Work Hours in a year

1,800

Fully Loaded Company Average Hourly Rate $=$

$1,278,012,299 / 8,576.3 / 1,800$

82.79

Savings $=(10 \times 3,038) / 60 \times 82.79$

129,000

Efficiency Savings

59,520

PM Savings

188,520

\section{Total Savings}

\section{Estimate:}

The annual total life cycle cost savings is the increased efficiency of the existing preventive maintenance (PM) Program per the Do-It-Now (DIN) process plus the cost savings netted by redirecting corrective maintenance $(\mathrm{CM})$ funds towards PM activities through the DIN process. A more detailed explanation of this is given below.

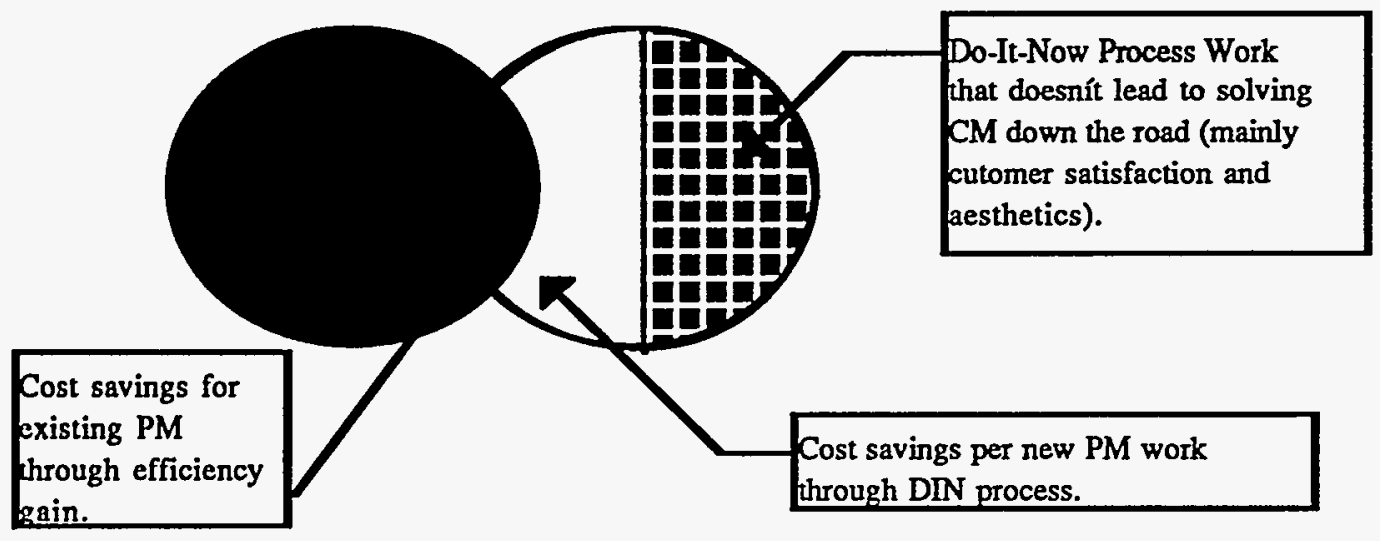




\section{Efficiency Savings}

The cost saving due to efficiency is calculated by assuming $10 \%$ of current PM activity is similar to DoIt-Now type work and that doing this work in the DIN system is $30 \%$ efficient than via MSRs. The DIN project team believes this is a conservative estimate, given that the average individual DIN job takes about one third the time taken by an equivalent MSR. Thus the total cost savings are calculated as follows:

FY Preventative Budget $X \%$ of current PM work similar to DIN work $X$ efficiency gain =.Cost , savings for existing PM through efficiency gain

The total budget for preventive maintenance in FY94 was $\$ 4.3$ million. The efficiency cost saving is

$$
\$ 4,300,000(.10)(.30)=\$ 129,000
$$

\section{Life Cycle Cost Savings from Increased PM}

The second part of the cost savings calculation is a more complicated, since it includes assumptions concerning life cycle models. A widely used commercial assumption is that each dollar spent in preventive maintenance results in two dollars in corrective maintenance savings through the life of the building. To calculate the additional money to be spent on preventive maintenance in the DIN system, the total cost of the DIN system is calculated as follows:

$$
\begin{array}{lr}
\text { DIN work team (9 FTE fully loaded) } 9 \times \$ 97,000= & \$ 873,000 \\
\text { Supervision (0.1 FTE fully loaded) } & 14,500 \\
\text { Material (15\% of labor) 778K (.15) } & 5,200 \\
& \$ 892,700
\end{array}
$$

Assuming that one third of DIN work will be applicable to PM (the lamper and painters will not contribute to PM, for example, and the other DIN workers will spend much of their time on corrective tasks), the total cost of PM in the new system will be $\$ 297,600$. If each dollar devoted to PM avoids two dollars in CM over the life of the facility, the total cost savings will be $\$ 595,200$.

The avoided $\mathrm{CM}$ cost is not recovered immediately, but distributed throughout the lifetime of the facility. Estimates of facility life are complicated by considerations of changing missions and regulatory requirements, along with other unpredictable factors like accidents. The interior architectural and structural systems that DIN workers generally maintain are often remodeled long before their design life expires. Therefore textbook estimates based on design lifetime may not be useful in this application. Given the imprecise nature of the other assumptions in this calculation, assuming these system have a useful life of 10 years seems reasonable. Using a straight line distribution of cost savings, the annual savings of corrective maintenance costs due to investment in preventive maintenance are:

$$
\$ 595,200 / 10=\$ 59,520
$$

Summary,

Annual Life Cycle Cost Savings = Cost Savings due to efficiency gain + Cost Savings due to investment in $\mathrm{PM}=\$ 129,000+59,520=\$ 188,520$

\section{SUPERVISORY OVERHEAD}

DINable MSRs $=3,038$ 


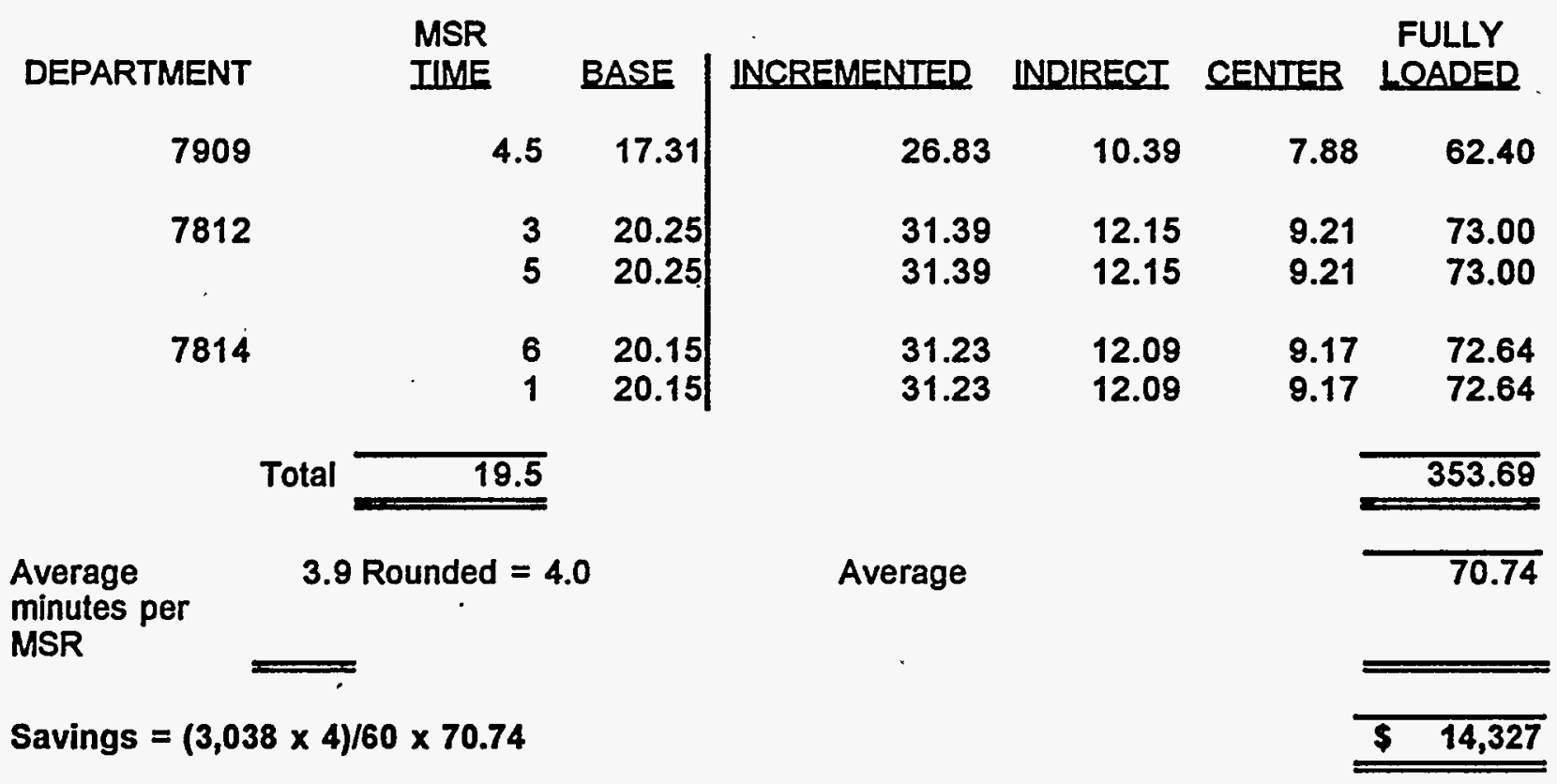




\section{COST OF INCREASED WORK}

Increased Work Cost" $=$

$\$(38,168)$

"Cost of increased work is the cost of the additional work the-DIN teams would generate by.doing .. $\because$ maintenance and repairs that the building tenants probably would not have requested (because they are preventive or in areas that are not easily-visible-to tenants) m.To estimate-this-cost, MSRs from FY94,... the last full fiscal year before the DIN pilot began, were examined. In that year, the $\mathbf{2 8}$ buildings that were to be included in the DIN pilot generated $660 \mathrm{MSRs}$ for maintenance and repairs that:would.havebeen eligible for DIN. In FY95, the DIN pilot generated the equivalent of 729 MSRs: Thus, the assumption is that DIN generated the equivalent of 69 more MSRs than would have been reported in the absence of the DIN system.

To calculate the cost of each of the DIN equivalent MSRs, the total cost of the DIN prototype was calculated as follows:

Total DIN work hours X Rate per hour X 1.15 = Total cost

where 1.15 is the adjustment for the cost of materials, which averages $15 \%$ for the entire Operations .. and Maintenance Center. For FY94, this calculation is as follows:

1624 manhours $X \$ 54.02$ per manhour (fully loaded) $X 1.15=\$ 100.887 .75$

Dividing this by the number of equivalent MSRs gives $\$ 138.39$ per equivalent MSR.

The new DIN system employs the equivalent of four work teams (of the 9 FTEs doing DIN work, one, the lamper, can be expected to generate no new work), so the projected number of excess equivalent MSRs is 276 and the additional cost is

276 MSRs (equiv.) X $\$ 138.39$ per MSR (equiv.) $=\$ 38,168$ 


\section{Appendix 3}

Reengineering Questions and Answers

The following questions are taken from Process Modeling and Innovation by Process Solutions International, Inc. They are structured in chronological order by phases of the reengineering project. The answers were formulated by the reengineering team through during the reengineering project. -In some senses,... then, they are the raw material from which the new-DIN system and -this reportwere constructed.

\section{Step \#1-Identify the Current Process}

Step 1.1-Determine the critical processes

How and why did an interest in improvement arise?

The Do-It-Now (DIN) pilot program showed the possibilities for decreased costs, increased customer satisfaction, and increased efficiency in structural maintenance. In view of the probability of declining maintenance budgets, the efficiency and cost improvements are attractive. In addition, customer.satisfaction improvements will be necessary to ensure the survival of the Sandia maintenance organization.

Is there a particular area of concern?

Cost and customer satisfaction.

Who is the customer and what are his/her needs?

The customers of this process include the following: residents of the buildings

zone manager

general facility staff

other maintenance groups

Is it necessary to improve the process because of newly established goals or objectives?

No, although the magnitude of budgetary pressures is new.

Is the problem a cross-functional one? If so, should more consensual teams be formed to resolve it?

The problem is cross functional in that in involves maintenance, engineering, and budget disciplines. All of these disciplines are represented on the team, along with representatives of the customers' perspective.

Is there anything to compare the process to and model it after?

The DIN pilot program is the model for initial ideas concerning the design of the new process. A search for useful models elsewhere in government and industry will be undertaken. 
What products or services does the process produce?

Safe and pleasant work areas for tenants

Corrective action on deficiencies for tenants, zone manager, and building operators

Inspection data for other maintenance organizations

- Recommendations for other repairs (MSRs) -for zone managers and building tenants

The detailed scope (for example, which systems will be included, how much preventive maintenance will be performed, etc.) will be decided during the design phase.

Who is the customer of the defined process (i.e., consumer, next department, next company, etc.)?

Unlike many Facilities processes, the primary customers of this process are individual employees and other residents of Sandia buildings. In addition, the tenant organizations receive information concerning the condition of their buildings and recommendations for major repairs.

How does the customer evaluate the determined output?

Since most of the repairs are requested by the customers, customers will be able to determine whether the repairs have been made. They may be less able to determine if preventive maintenance meets their requirements.

Is there any form of feedback available on customer satisfaction?

No, although the DIN prototype includes a point-of-service survey card for customer feedback.

Is this process comparable to others within or outside of the organization? Every major organization has a corrective maintenance process of some sort, although the form and operation differs between organizations.

\section{Worksheets}

Complete Process Identification Worksheet \#1

Complete top half of Process Identification Worksheet \#2 


\section{Process Identification Worksheet \#1}

\section{Instructions}

1) Identify the major process you are examining.

2) Subdivide the major process and identify the subprocesses and their output.

\section{Major Process}

\section{Do-It-Now Building Maintenance}

\begin{tabular}{|l|l|l|l|}
\hline $\begin{array}{l}\text { A. Corrective } \\
\text { Maintenance }\end{array}$ & $\begin{array}{l}\text { B. Emergency } \\
\text { Maintenance }\end{array}$ & $\begin{array}{l}\text { C. Preventive } \\
\text { Maintenance }\end{array}$ & D. Operations \\
\hline $\begin{array}{l}\text { E. Land- } \\
\text { scaping }\end{array}$ & F. Utilities & $\begin{array}{l}\text { Work Control } \\
\text { (support) }\end{array}$ & $\begin{array}{l}\text { Management } \\
\text { (support) }\end{array}$ \\
\hline $\begin{array}{l}\text { Engineering } \\
\text { Support } \\
\text { (support) }\end{array}$ & & & \\
\hline & & & \\
\hline & \multicolumn{3}{|c|}{ Subprocesses } \\
\hline
\end{tabular}

\section{Subprocess Outputs:}
A. Repairs to structures, systems, or components; technical data for other maintenance organizations
B. Repairs to structures, systems, or components; technical data for other maintenance organizations
C. Preventive maintenance services for structures, systems, or components, technical data for other maintenance organizations, maintenance recommendations for customer organizations
D. DIN Work Plans, DIN work logs
E. Landscape maintenance services
F. Repairs to external utilities and infrastructure 


\section{Process Identification Worksheet \#2}

Process Name: DIN Building Maintenance

Type of Process [X] Main [ ] Subordinate-name of main process:

Process Owner: Ed Williams

Description of the Process: A building maintenance team identifies and corrects deficiencies in building interior structure on periodic visits. Maintenance requirements are determined by team inspection and by communication with representatives of building occupants.

Critical Measures of the Process:

\begin{tabular}{|l|l|l|l|}
\hline Measure \#1 & Measure \#2 & Measure \#3 & Measure \#4 \\
\hline $\begin{array}{l}\text { Customer } \\
\text { satisfaction }\end{array}$ & $\begin{array}{l}\text { Maintenance } \\
\text { manhours per job }\end{array}$ & & \\
& - & & \\
& & & \\
\hline
\end{tabular}

[ ] Additional measures are identified on an attached sheet

How do you know that the process works?

Customer feedback via forms distributed at end of DIN maintenance visit. Informal feedback from building occupants and management.

Completed by: $\mathrm{R}$. Matthews

Date: 4/3/96 
Process Rating Worksheet

\begin{tabular}{|l|l|}
\hline Part I & $\begin{array}{l}\text { Part II } \\
\text { Identified Processes }\end{array}$ \\
\hline DIN Building Maintenance & $\begin{array}{l}\text { Not enough personnel to ensure } \\
\text { sufficient frequency of visits } \\
\text { Lack of building.crafts other than } \\
\text { structural }\end{array}$ \\
& \\
& \\
\hline
\end{tabular}


Step 1.2 -Measure the Identified Process

What are the critical measures of the process?

Customer satisfaction

Maintenance manhours per job

How is customer satisfaction being measured?

- A form left with building occupant representatives after each visit.

What performance data is available to assess the current performance of the process?

MAXIMO (or AMM) maintenance database, DIN workers logs.

\section{Worksheets}

Complete the bottom half of the Process Identification Worksheet \#2.

Step 1.3 - Rate the Process Performance

Worksheets

Complete the Process Rating Worksheet 


\title{
Step \#2: Establish Scope
}

\author{
Step \#2.1 Identifying the Stakeholders
}

Orient the Process Sponsor(s)

Confirm each others understanding of the project. Jim Kadlec reviewed project direction with Ed Graham a second time.

Build an understanding of the sponsor's rationale for initiating the effort. - ..... . Sponsor concerned with Org. 7800-reputation and costs of performing maintenance.

Must reduce overhead costs.

Confirm with the sponsor that those who will be assigned to the effort will be the most appropriate individuals from a knowledge and authority standpoint.

Team membership reviewed with sponsor.

Ensure that the sponsor is willing to address the particular issue using the reengineering approach (versus a functional approach). Sponsor supports the reengineering effort.

How does the sponsor define the problem (or describe the process) in his or her own words?

7800 needs to reorganize and change ways of business in order to get cost savings. Need to do small things now to cause cost savings and restructuring instead of tackling the whole center problem with cost. There should be numerous parallel efforts designed to complement each other. Customer appreciation of maintenance must increase. Space charge-back costs must be seen by the customer as worth the cost.

Redefine the sponsor's words in terms that indicate an improvement in customer satisfaction.

Maintenance must be performed more cost-effectively with reduced hours and with increased customer contact and communication.

What goals does the sponsor believe are most critical to ensure the success of his or her area of responsibility?

Reduced cost, faster response, better public relations, and consistently good work quality. 


\section{Identify and Orient the Process Stakeholders}

What resources are available to carry out process improvement? Funding for the indirect personnel is provided by AMCO Funding for the directs is provided by Ed Graham. Personnel from Org. 7800, 7900, communications, and external sources are on the team to provide different viewpoints on the process. On-going DIN pilot project.

Who is leading the project and-is/are he/she/they ready to commit to the project?

Jim Kadlec is the team leader and is contributing $100 \%$ of his time to the project.

What are the benefits/drawbacks of a project such as this?

Benefits: Well trained crew of craft, less cost/greater efficiency of maintenance, more satisfied customer, documented process and metrics, increased worker satisfaction, increased worker flexibility, less scheduled backlog of work, increased knowledge of the work process, reduced management overhead.

Potential Drawbacks: Current rigid culture could prevent change, lack of union support for the process, lack of Sandia Labor Relations buy-in, not all personnel fit into this model of working, not all types of work fit the process, possible redundancy of efforts, possible turf issues to overcome, will there be enough work to keep the process participants busy, could result in increased costs in some cases, lack of management support, management qualifications for leading the process.

Why is the project being introduced and is this the right time for it?

The project is being introduced at this time due to potential DOE funding cutbacks and a search for ways to reduce maintenance costs. Pilot project results and favorable customer response. Interaction with space chargeback (customers can finally see where their space chargeback dollars are going).

Has everything, including future plans, been considered?

To the best of the teams ability.

Confirm that the sponsor(s) will take the lead role in gaining commitment from the stakeholders.

The sponsor(s), Ed Graham and Ed Williams, have committed to making this project happen. Vice President Lynn Jones is interested and committed.

Which individuals can best represent these organizations (based on who is affected by the process) and have authority to make changes?

Team members with management support and steering committee input. 
Have the stakeholders been oriented to the reengineering methodology? In process. Orientation takes place on just-in-time basis in consultation with Jeff Lowenthal.

\section{Step *2.2 Set Project Mission and Goals}

Who is the primary customer and what are the products/services that the process delivers?

Customers: See Mapping the DIN Process. Building residents, other maintenance organizations, zone managers, organizational facilities coordinators (OFCs), ES\&H coordinators, building coordinators, DOE (as building owners), Facilities Engineering Standards Program (for engineering. design improvements).

Products/services: See Mapping the DIN Process. Provide safe and pleasant work areas to the customer, inspection input to other maintenance organizations, compliance with DOE orders and other regulations for customers' space.

What are the inputs to the process (i.e., people, methods, material, equipment, environment)?

See Mapping the DIN Process. MSRs, building DIN schedule, asbestos reports, DIN building work plan, maintenance materials (from warehouse and vendors).

What are the perceived boundaries of the process?

See DIN process flowchart. Modification work vs. Maintenance, all craft trades, small-scale periodic activities on non-critical equipment, short-term tasks, real property only, unknown scope (to be defined later in the process), DIN/MSR interface, onsite properties only

Which organizations are included within the boundaries?

See DIN process flowchart.

Is the project manageable given these boundaries?

Yes.

Are there any potential problems or challenges using these boundaries?

Must prove the worth of the process (cost-effectiveness), current pressure to reduce staff, turf issues, reallocation of resources, staying within unidentified limits of work, management support for defined boundaries.

\section{Clarify Assumptions}

Are there any assumptions or constraints that will affect the type of changes that can be made to the process? 
Expected level of improvements - No

Resource (time and head count) constraints. - Yes

Cost limitations. - Yes

Areas or issues that are off-limits. - Yes

Potential changes that may impact the process. - Very possible

Potential organizational conflicts. - Very possible

Other assumptions or constraints.

Management support

On-going union contract negotiations

Set Preliminary Project Goals

What tentative improvement objectives can be established (quality, cost, timing objectives)?

(see Project Profile Sheet)

Is there adequate challenge (stretch) in these goals?

Yes

Do the goals provide enough excitement so that others will want to be involved in attaining them?

Yes

\section{Discuss Initial Time Frames}

What would appear to be a reasonable time frame to accomplish these goals? Each project goal is shown on the attached project schedule. Schedule is aggressive but realistic.

Who would need to-agree on this time frame?

Team members and sponsor.

Step \#2.3 Structure and Select Team Members

Which individuals have the greatest knowledge of; experience in, and influence over their portions of the process?

DIN team members, planners, team leader, supervisor, Facilities business office.

Who must be contacted to ensure these people are available for the effort?

Ed Williams, who has agreed to negotiate for team members' time.

Who might serve as alternates if they are unavailable?

Requested team members are available. 
Orient team members on the ground rules and meeting conduct. Completed.

Provide the team with preliminary decisions made by the sponsor(s), the leader, and the stakeholders.

Completed.

Identify and resolve any issues or concerns brought up by the team.

Completed. 
Develop a work plan that covers:

- Tasks to be performed during the reengineering effort.

- Individuals responsible for those tasks.

- Individuals who will assist or support.

- Estimated timing for completing the task. Project plan completed, individuals will be assigned to the tasks as the project progresses.

\section{Formal Contract}

Is there a common agreement by the sponsor(s), the stakeholders and the leader with regard to:

- project assumptions

- project goals

- clarity of tasks and assignments

- review process by senior management Yes. See Project Plan

What logistical agreements have been made by the team (i.e., frequency of meetings, length of process, requirements of team members, review by stakeholders)?

Meeting frequency, team responsibilities, length of reengineering effort, percentage of time required from team members for the project. See Project Plan

Who will do what work between meetings:

- Meeting preparation

- Data collection

- Data analysis

Assignment of activities is listed on project schedule in the Project Plan.

What plans have been made to formally recognize the efforts of team members (e.g., build into performance objectives, discuss at business review meetings)? Issuance of a SAND Report and nomination for a President's Quality Award. Addition of reengineering activities to the annual Performance Management Form (PDF). 


\section{Stakeholder and Membership Verification Worksheet}

Process Name: Do-It-Now Building Maintenance

\section{Part I - Stakeholders}

Stakeholders are usually -members of management and -are-individuals who are: most able and willing to improve the specific process. In the space below, enter the primary stakeholders-and their selection criteria.

\begin{tabular}{|c|c|c|c|}
\hline Participating & Stakeholder & \multicolumn{2}{|c|}{ Criteria } \\
\hline 7800 & Managers & $\begin{array}{l}\text { Authority } \\
\text { Interest }\end{array}$ & $\begin{array}{l}\text { Influence } \\
\text { Knowledge }\end{array}$ \\
\hline & $\begin{array}{l}\text { Craftspersons, graded } \\
\text { employees }\end{array}$ & Interest & Knowledge \\
\hline Metal Trades Council & Union leadership & $\begin{array}{l}\text { Influence } \\
\text { Knowledge }\end{array}$ & Interest \\
\hline $\begin{array}{l}\text { Customer Funded } \\
\text { Program }\end{array}$ & Mike Quinlan & $\begin{array}{l}\text { Influence } \\
\text { Knowledge }\end{array}$ & Interest \\
\hline 7000 & Lynn Jones & $\begin{array}{l}\text { Authority } \\
\text { Interest }\end{array}$ & $\begin{array}{l}\text { Influence } \\
\text { Objectivity }\end{array}$ \\
\hline $\begin{array}{l}\text { Lab and External } \\
\text { Management }\end{array}$ & $\begin{array}{l}\text { Line Implementation } \\
\text { Working Group, }\end{array}$ & $\begin{array}{l}\text { Influence } \\
\text { Objectivity }\end{array}$ & Interest \\
\hline 7312 & $\begin{array}{l}\text { Al Spencer - Zone } \\
\text { Managers }\end{array}$ & $\begin{array}{l}\text { Influence } \\
\text { Knowledge }\end{array}$ & Interest \\
\hline DOE/KAO & Milt West & $\begin{array}{l}\text { Authority } \\
\text { Interest } \\
\text { Knowledge }\end{array}$ & $\begin{array}{l}\text { Influence } \\
\text { Objectivity }\end{array}$ \\
\hline DOE/AL & Tom Gutierez & $\begin{array}{l}\text { Authority } \\
\text { Interest } \\
\text { Knowledge }\end{array}$ & $\begin{array}{l}\text { Influence } \\
\text { Objectivity }\end{array}$ \\
\hline
\end{tabular}




\section{Part II - Team Members}

List all the organizations who play a role in the process being explored and name the team member that currently represents each of them on the team.

\begin{tabular}{|l|l|l|}
\hline Participation Organization & \multicolumn{1}{|c|}{ Team Member } & \multicolumn{1}{|c|}{ Criteria } \\
\hline DIN Maintenance & Jim Kadlec & Primary/support Process \\
\hline 7800 - Maintenance crafts & Shannon Letourneau & Primary/support Process \\
\hline 7815 - Planning & Luis Apodaca & Primary/support Process \\
\hline 7801 - Budgeting & Sam Jojola & Primary/support Process \\
\hline $\begin{array}{l}7907 \text { - Facilities } \\
\text { Engineering Standards }\end{array}$ & John Romero & External Customers \\
\hline Customers & $\begin{array}{l}\text { Ad hoc members (See } \\
\text { Project Profile sheet in } \\
\text { Project Plan }\end{array}$ & External Customers \\
\hline Team support & $\begin{array}{l}\text { External Viewpoint- } \\
\text { Lynnwood Dukes } \\
\text { Communications-Bruce } \\
\text { Hawkinson } \\
\text { Documentation-Bob } \\
\text { Matthews } \\
\text { Process facilitation-John } \\
\text { Coffman }\end{array}$ & \\
\hline
\end{tabular}




\section{Project Mission and Goals Worksheet \#1}

Process Name: Do-It-Now Building Maintenance

Type of process: $\sqrt{ }$ Main__Subordinate - Name of main process:

Process Owner: Ed Williams

\section{Project Mission/Charter:}

A mission is a clear statement of what the team is expected to accomplish in the way of improvements to the process.

Design, build and implement a proactive, building-based maintenance process that greatly increases customer satisfaction and decreases cost by identifying and correcting structural, electrical, mechanical, landscaping, etc. problems on a scheduled, periodic basis per building. Explore possibilities for expanding the pilot process to preventive and programmatic maintenance as well as small modifications

Completed by: Team members

Date: $8 / 16 / 95$ 


\section{Project Mission and Goals Worksheet \#2}

Process Name: Do-It-Now Building Maintenance

Type of process: Main Subordinate - Name of main process:

Process Owner: Ed Williams

Project Goals:

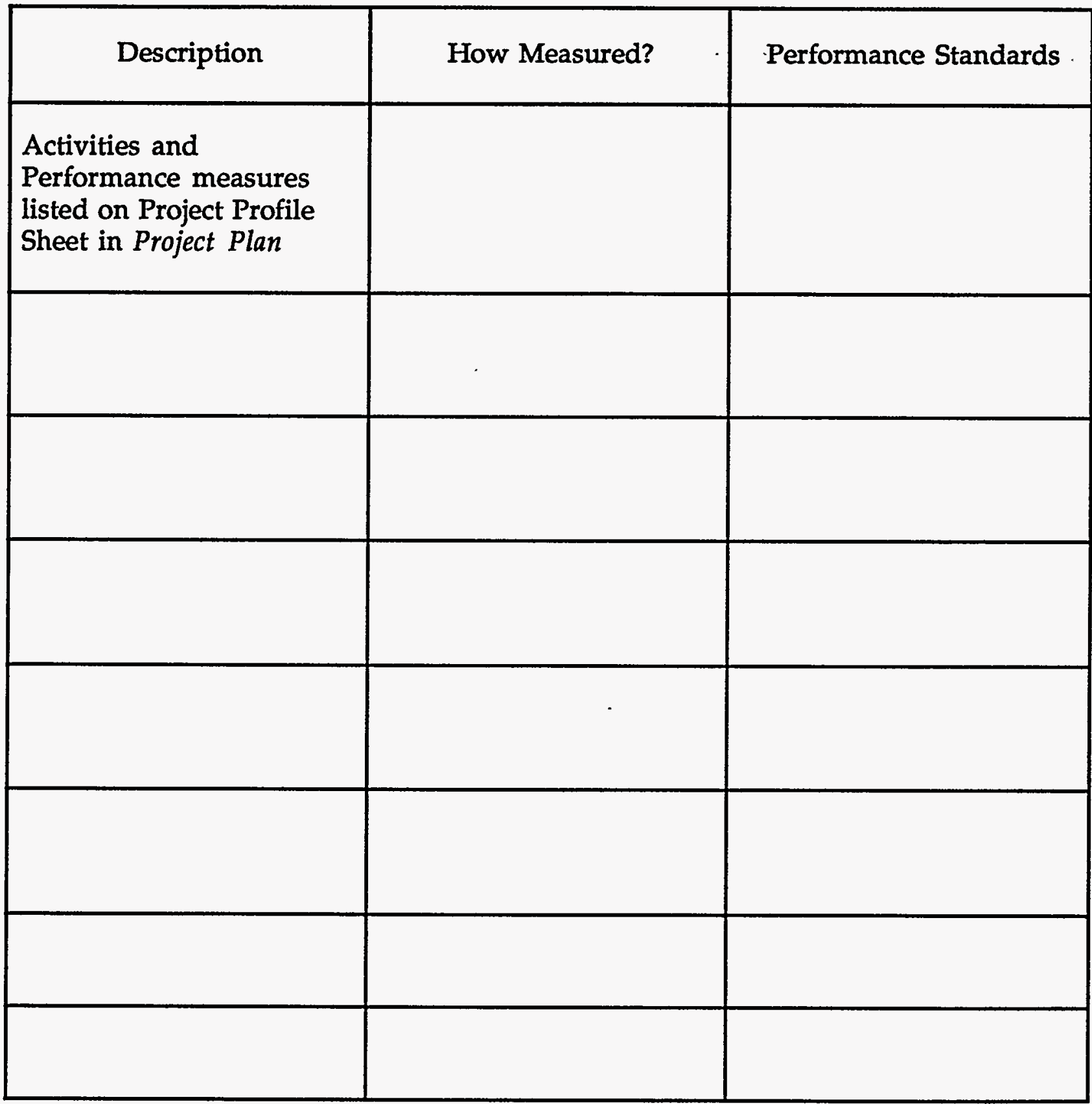




\section{Preliminary Project Planning Worksheet}

Process Name: Do-It-Now Building Maintenance

Process Owner: Ed Williams

\begin{tabular}{|c|c|c|c|}
\hline Action Item & Target Date & $\begin{array}{c}\text { Primary } \\
\text { Responsibility }\end{array}$ & Support \\
\hline $\begin{array}{l}\text { Definition/docu- } \\
\text { mentation of } \\
\text { identified process } \\
\text { Flowcharts } \\
\text { Integrated Flow } \\
\text { Diagrams } \\
\text { Process Mapping } \\
\text { Worksheets } \\
\text { Process Constraint } \\
\text { Analysis } \\
\text { Cultural Factor } \\
\text { Analysis } \\
\text { Detailed } \\
\text { Procedures } \\
\text { Requirements } \\
\text { Measurements }\end{array}$ & $\begin{array}{l}\text { Dates and } \\
\text { Responsible } \\
\text { Individuals listed } \\
\text { on Project } \\
\text { Schedule in Project } \\
\text { Plan }\end{array}$ & & \\
\hline
\end{tabular}




\begin{tabular}{|c|c|c|c|}
\hline $\begin{array}{l}\text { Analysis, Design, } \\
\text { and } \\
\text { Implementation } \\
\text { Analyze Data } \\
\text { Potential Short } \\
\text { Term } \\
\text { Improvements. } \\
\text { Pilot Project } \\
\text { Implementation } \\
\text { Plan }\end{array}$ & & : & s \\
\hline Completed by: & L. Dukes & Date: $8 / 21 / 95$ & \\
\hline
\end{tabular}




\section{Step \#3: Map and Analyze the Process}

\section{Before Beginning This Process}

Confirm the boundaries determined by the sponsor and the leader with the entire team, verifying the:

- Customer(s).

- Start of the process.

- Process products/services.

- Process inputs.

Complete, see Mapping the DIN Process.

\section{Step *3.1 Flowchart the Process}

Develop a macro process flowchart at the current level of knowledge. Make sure that the flowchart represents what actually occurs - not what the procedures say "should" occur. Make sure to capture how variations to the normal process are handled.

See Figure 1.

Do all the team members concur with the process flowchart? If not, find and resolve the reasons for conflicting views.

Yes.

Steps to create a flowchart

What work product, information, or materials are needed as inputs to this activity?

DIN building schedule

DIN building work plan

Asbestos report

ES\&H-related problem reports

Warehouse inventory material

Other materials

Plans

What are the requirements of these inputs?

None documented for current process.

Does an interface exist between this activity and the preceding one?

- - Yes. - Interfaces with asbestos, ES\&H, and warehouse organizations are welldefined by those organizations. Interfaces with planning and scheduling activities are defined in the DIN process. 
Does the activity involve a decision that leads to either of two output states?

Decision is before process begins, whether to use DIN or MSR process.

\section{Step \#3.2 Create an Integrated Flow Diagram of the Process}

Develop a macro Integrated Flow Diagram (IFD) at the current level of communications. Make sure that the flowchart represents.what actually . occurs - not what the procedures say "should" occur. Make sure to capture how variations to the normal process are handled. See DIN IFD, Figure 2.

Do all the team members concur with the IFD? If not, find and resolve the reasons for conflicting views.

Yes.

Steps to create an Integrated Flow Diagram

What external entities are needed as inputs to this activity?

What are the primary activities?

What files exist in the process?

What major pipelines exist between the activities, files and external entities?

Step \#3.3 Complete the Process Mapping Worksheet

Worksheets

Complete the Process Mapping Worksheet using the questions below as guidelines

Enter the process inputs

Process inputs are the equipment, materials, methods, and environment necessary to produce the products and services of the process. People who take the inputs and act upon them are the central resource The information for this section can be obtained directly from the flowcharts and Integrated Flow Diagrams.

Enter the process outputs

The process outputs are the products or services produced by the process. List the products and services produced by the process here. 
Enter the specific process targets

Define the objectives, goals, and targets that the process must achieve to meet product and service quality expectations of the customers. These targets are a direct translation of the specific customer targets.

\section{Complete the "voice of the process" section}

What critical characteristics of the process can be improved so that the products : and services will meet or exceed the customers needs and expectations? ........

What targets (improvements) should be established so that the critical characteristics will meet or exceed the customers' needs and expectations?

What additional information is needed to define these targets?

What should be measured inside or during the process?

Is there a system for collecting information on the performance of the process?....

Do the measurements being used to assess the voice of the process reflect the voice of the customers?

Is the process currently meeting the established targets for the critical characteristics of the process?

Complete the "voice of the customer" section

How well does the process satisfy your customer(s)?

How do you find out whether you are meeting the needs and expectations of your customer(s)?

Do the measures being used assess the voice of your customer(s)?

What should be measured inside or during the process?

Is there a system for collecting information on the performance of the process?

Do the measurements being used to assess the voice of the process reflect the voice of the customers?

Is the process currently meeting the established targets for the critical characteristics of the process?

Complete the catalyst event section 
The catalyst event is the event that signals the beginning of the process. The catalyst establishes the initial boundary of the process. The catalyst event can be found on the first-level drawing of the IFD or the level-1 flowchart.

\section{- Complete the customer section}

Customers are the users of the products or services produced by the process. Customers are the ultimate judges of the quality of the process outputs. Furthermore, the primary -customer-is -the most important-customer for the specific product or service, the principal reason the process exists and the end boundary of the process. The primary customer should be identified here.

Complete the customer needs and expectations section

The material for this section can be found on either of the mapping pictures. If the team cannot identity the customers' needs and expectations in one of the mapping pictures, the information can be obtained from the process sponsor or stakeholders.

Complete the specific customer targets section

Specific customer targets translate customers' needs and expectations into specific, quantifiable attributes that can be used to assess the quality of the product or service.

\section{Step \#3.4 Complete a Process Constraint Analysis}

Complete a Process Constraint Analysis by surveying those individuals who are involved in completing the work in the current process.

\section{Step \#3.5 Complete a Cultural Factor Analysis}

Complete a Cultural Factor Analysis by surveying those individuals who are involved in completing the work in the current process. 


\section{Process Mapping Worksheet}

Process Name: Do-It-Now Building Maintenance

Inputs .

DIN building schedule

DIN building work plan

Asbestos report

ES\&H-related problem reports

Warehouse inventory materials

Other materials

Plans

Process owner name: Ed Williams

Title:Manager, Facilities Shared Systems Department

What are the specific process target(s)?

Other than true planning hours $=3$ hour $/$ day ( -9 hours)

Craft hours $=2.8$ per MSR (-2 hours)

Number of MSRs $=22,000$ per year $(-7,000)$

What is the voice of the process?

Customer feedback forms

Work logs

MAXIMO (work control system) reports mal)
tenance
logs mal)
tenance
logs
DIN repairs and modifications

Notification to other crafts of non-DIN work

List of complete and pending items

Identification of additional project or restoration work

Customer feedback (formal and infor-

Referrals for remodeling and maintenance work

Work logs
Outputs 
What is the process's catalyst event?

Beginning of next scheduled DIN building visit

Who is the customer(s) of the process?

Building occupants

Building representatives (ES\&H coordinators, Organizational Facilities Coordinators, building coordinators)

Other maintenance organizations

DOE

What are the customer's needs and expectations?

Open, courteous communications with DIN team

Effective repairs and modifications

Neat cleanup after repair work

Improved facility condition, life extension

What are the specific customer targets?

Customer satisfaction survey results 4.5 or above for each category ( +.5 to 1.0 )

What is the voice of the customer?

Customer feedback form 


\section{Process Constraint Analysis Worksheet - Team Summary}

Process Name:_Building Maintenance Work Control Process

\begin{tabular}{|c|c|c|c|}
\hline Constraint & $\begin{array}{c}\text { Where in the } \\
\text { process did it } \\
\text { occur? }\end{array}$ & $\begin{array}{l}\text { Why do you think } \\
\text { it happened? }\end{array}$ & $\begin{array}{c}\text { What impact does } \\
\text { it have on your } \\
\text { job? }\end{array}$ \\
\hline $\begin{array}{l}\text { 1. Timely support } \\
\text { unavailable }\end{array}$ & $\begin{array}{l}\text { During execution } \\
\text { when other craft } \\
\text { work is required }\end{array}$ & $\begin{array}{l}\text { Poor communi- } \\
\text { cations between } \\
\text { crafts, heavy } \\
\text { workload }\end{array}$ & $\begin{array}{l}\text { Difficult to } \\
\text { complete jobs that } \\
\text { require more than } \\
\text { one craft }\end{array}$ \\
\hline $\begin{array}{l}\text { 2. Special } \\
\text { equipment } \\
\text { unavailable }\end{array}$ & During execution & $\begin{array}{l}\text { Poor planning, } \\
\text { equipment in poor } \\
\text { repair }\end{array}$ & $\begin{array}{l}\text { Delays while } \\
\text { equipment is } \\
\text { located and } \\
\text { procured }\end{array}$ \\
\hline $\begin{array}{l}\text { 3. Unanticipated } \\
\text { priority shifts, } \\
\text { work interruptions }\end{array}$ & During execution & $\begin{array}{l}\text { Lack of system for } \\
\text { assigning priorities, } \\
\text { lack of will to } \\
\text { follow system }\end{array}$ & $\begin{array}{l}\text { Delays from } \\
\text { interruptions to do } \\
\text { "higher" priority } \\
\text { work }\end{array}$ \\
\hline $\begin{array}{l}\text { 4. Excessive } \\
\text { workload }\end{array}$ & Throughout & $\begin{array}{l}\text { Poor planning of } \\
\text { work requirements } \\
\text { and staffing }\end{array}$ & $\begin{array}{l}\text { Delays in } \\
\text { responding to } \\
\text { customer requests }\end{array}$ \\
\hline 5. Poor morale & Throughout & $\begin{array}{l}\text { No reward for } \\
\text { conscientious } \\
\text { performance, no } \\
\text { sanctions for poor } \\
\text { performance }\end{array}$ & $\begin{array}{l}\text { Difficult to justify } \\
\text { working up to } \\
\text { potential }\end{array}$ \\
\hline $\begin{array}{l}\text { 6. Excessive } \\
\text { specialization }\end{array}$ & Throughout & $\begin{array}{l}\text { Rigid division of } \\
\text { work and workers }\end{array}$ & $\begin{array}{l}\text { Lowered employee } \\
\text { satisfaction, delays } \\
\text { waiting for } \\
\text { specialists. }\end{array}$ \\
\hline
\end{tabular}




\section{Cultural Factor Analysis Worksheet}

\section{Process Name:}

In the space below, rate each of the cultural factors by using the rating scales below.

\section{Optimum Factors}

Rating: -5 to $+5,0=$ just right

\begin{tabular}{c|l|l|l|}
\cline { 2 - 4 } $\begin{array}{c}\text { Job } \\
\text { Title }\end{array}$ & Empowerment & Variety & Feedback \\
\hline $\begin{array}{c}\text { Crafts- } \\
\text { man } \\
\text { (non- } \\
\text { DIN) }\end{array}$ & -2 & 0 & -4 \\
\hline $\begin{array}{c}\text { Crafts- } \\
\text { man } \\
\text { (DIN) }\end{array}$ & 0 & 0 & \\
\hline & & & \\
\hline & & & \\
\hline & & & \\
\hline & & & \\
\hline & & & \\
\hline & & & \\
\hline
\end{tabular}

\section{Maximal Factors}

Rating: 0 to $10 ; 0=$ none, $10=\mathbf{a}$ great deal

\begin{tabular}{|l|l|l|}
\hline Respect & Big Picture. & . Growth: \\
\hline 6 & 5 & 2 \\
& & \\
\hline 7 & 8 & 8 \\
& & \\
\hline & & \\
\hline & & \\
\hline & & \\
\hline & & \\
\hline & & \\
\hline
\end{tabular}




\section{Step \#4: Create the Ideal}

\section{Assessing the Readiness to Generate Alternative Processes}

Have all appropriate stakeholders (including customers) been involved in progress to date?

Yes. Customer representatives are included on ad hoc committee, other stakeholders are represented in steering committee.

Do all team members understand the way the process works today, with quantitative and qualitative data to support that understanding?

Yes, to varying degrees. The steering committee members are heavily involved with current process and DIN pilot

Has the process been analyzed to a level of detail that lends itself to generating process changes?

Yes.

Assess the performance and efficiency of the process

Has the team collected data over time and identified/correct any trends or variability issues (special causes)?

Variability in MSR cost and cycle time arises mostly from two sources. The major source is size of the task; larger requests take longer and cost more. Special materials requirements are the second major source. For example, carpet is expensive and procurement can cause delays. System furniture can also be problematic.

Have all team members been apprised of the data?

Yes

What other information is needed to increase the general understanding of the potential opportunities? Additional information? Detailed analysis of a subprocess?

Experience with the DIN process in the past year has convinced participants, management, and customers of its potential.

What factors may be causing the difference between the voice of the process and voice of the customers?

See the discussion of variability sources, above. Customer requirements for routine maintenance differ from those for more extensive repairs and modifications. 
What other analytic tools could assist in identifying or substantiating the causes of these differences? What assistance is needed to use these tools?

Examination of the work control databases is ongoing.

Are the performance factors for people within the process consistent with the intent of the process (performance expectations, feedback to people within the process, compatible rewards)?

Evidently. Process participants were primary developers of DIN process.

Worker satisfaction is high.

Step \#4.1 Whitepaper the Process

Verifying and Preparing

Using the data from the analysis stage and from benchmarking, how much change is needed to reach project goals?

Expansion of the DIN pilot process to increase number of buildings and frequency of visits.

What kind of visioning process is most appropriate?

Are there boundaries or limitations placed around the visioning process?

The vision is limited to expansion (in size and scope) of the DIN process to the extent of available resources

What happens after the team introduces various alternatives? Steering committee decides between them.

How will those alternatives affect the team members and the encompassing organizations?

Primarily by determining the scope and amount of DIN work.

What form of criteria will the team use to determine the impact and potential success of the changes they will be introducing?

Criteria are stated in the reengineering project plan

\section{Ideal Generation}

What would your ideal process look like, ignoring all the constraints of the present?

See process description 
Which activities are crucial to meeting customer demand? Scheduling

Communications with customers concerning requirements

Estimating for customer-funded work

Which assumptions about the process are most apparent and how can these assumptions be changed for maximum improvement?

The paradigm for the present work control process is reactive response to customer requests. Changing to a proactive process of continuous inspection and correction should result in significant improvement.

Have the team brainstorm and list as many ideas that they can for improving the process, given the boundaries established.

Done, see minutes.

Make sure the team has designed the "perfect" process, ignoring the constraints of the present.

Not all constraints were ignored in the design process. In particular, the team decided to retain the essential features of the DIN pilot process because of its. demonstrated success in improving customer satisfaction.

Has the team explored alternatives that could be developed if certain constraints or assumptions about the process were removed?

Constraints that were relaxed in the design process included resource constraints (how would the process look if all the desired resources were available?), current management arrangements, etc.

Has the team also explored how these constraints can be removed or satisfied in a different way?

Yes. Matrixed personnel assignments could address resources constraints, and new management alignments (zone management, etc.) could be put in place. Since the management situation is so fluid, the process was designed to operate under a variety of reporting arrangements.

Has the team made good use of benchmarking (both inside and outside the company) to provide alternative ways of handling the process?

Yes. See benchmarking reports in minutes.

Step \#4.2 Compare the actual process to the ideal; and Step \#4.3 Assessing the Gaps

Can the team estimate the improvement that will result from the recommended changes to the process?

See cost savings estimate. 
Will these changes allow the process to meet the goals of the project?

Yes. Measures will be set in place to verify.

To what degree will the change reduce the difference between the voice of the process and the voice of the customer?

Experience with the DIN pilot shows the process will meet customer requirements for response and costs.

Will all stakeholders agree to the change?

Steering committee and Director are committed. Department managers are . waiting to see.

Will individuals in the process agree to the change? If not, what alternative action can the team take?

The primary criterion for selecting new team members is willingness to participate in the new process.

Finally, of all the alternatives, which has the greatest likelihood of success in terms of implementation and impact?

The proposed alternative. 


\section{Step \#5: Test the New Process}

\section{Step *5.1 Develop Pilot Objectives}

What is the team trying to accomplish by running the pilot?

Demonstrate that the DIN process is viable in the Sandia environment.

What would it take to create a realistic environment to run the pilot? The pilot will run in production as an integral part of the facilities maintenance process

What factors or characteristics would have to be present?

Available, qualified personnel, sufficient budget to acquire materials.

Who will review the results of the pilot to determine its success?

DIN work team, steering committee

Worksheets

Complete Pilot Planning Worksheet \#1.

\section{Step \#5.2 Develop Pilot Measures}

What measures or factors are key in determining whether a change to the process has been successful?

See reengineering project plan

What indicators will be measured and how will they be measured?

Customer satisfaction

Number of MSRs processed by Operations and Maintenance

Cost of maintenance

What tools can be used to measure the effects of these changes?

Customer feedback forms

MAXTMO database

Are the success indicators consistent with the process targets and the overall goals of the project?

Yes

Is the customer(s) of the process aware of the pilot and the objectives?

Yes (!) Communications plan is in place for roll-out.

Worksheets

Complete Pilot Planning Worksheet \#2. 
Is there an agreement as to the location of the pilot?

Yes. SNL/NM Tech Areas I and IV.

What are the risks and benefits of conducting the pilot at this location?

Risk: Large numbers of buildings and diverse space types.

Benefits: Includes the largest portion of SNL/NM personnel and buildings. Will provide a valid test of DIN process.

Who must be involved in authorizing the pilot?

Steering Committee

Director, 7800

Vice President, 7000

Do all the team members agree with the pilot objectives and success indicators? Yes

Which individuals should be involved with the pilot - both in changing the .... process and measuring the results?

DIN work team

Steering Committee

Have individuals who have not been involved to date in the project been oriented to the team's findings and the need to pilot the potential changes? Department managers and team supervisors in 7800 have been briefed on the process. A communications plan is in place to notify customers and other . stakeholders

Have the following items been clarified to all pilot participants:

What changes are taking place and why?

Yes

Where are changes taking place?

Yes

What new skills or perspectives are needed by the pilot participants?

Training plan is in place for new DIN work team personnel

Have the pilot participants been given the opportunity to indicate their concerns and have them addressed?

Yes, although new DIN work team members are yet to be selected. 
Worksheets

Complete Pilot Planning Worksheets \#3A and \#3B.

\section{Step *5.4 Conduct the Pilot}

Will be pilot be conducted on-line or off-line?

Most definitely on-line

Have individuals or organizations that may be affected downstream by changes during the pilot been contacted?

Communications plan is in place and customer communications are ongoing.

Has an action plan been developed that identifies:

Specific roles and responsibilities of participating individuals?

Yes

Specific tasks and activities for each individual?

Yes

Timing of each task?

Yes

A data-collection plan based on a planned statistical analysis?

Not in detail

Step \#5.5 Summarize the Findings

Determine the Improvement

Does the data support a statistical conclusion that there was improvement in the process?

Does the customer notice an improvement in the product or service?

Does the change being measured reflect what the customer really wants?

Summarize the Findings

How did the pilot results compare with what you originally thought would happen? 
Do you agree with the interpretation of the data, or do you feel there is more to it?

Can you think of any other processes where the data and.results gathered from this pilot can be applied? 


\section{Pilot Planning Worksheet \#1}

Process Name: Do-It-Now Building Maintenance

Process Owner._Ed Williams

What is the team trying to accomplish by running the pilot?

Demonstrate that the DIN process can be scaled to handle a significant . portion of all Sandia buildings efficiently and effectively.

Who will review the results of the pilot to determine if it's a success?

\begin{tabular}{|l|l|}
\hline \multicolumn{1}{|c|}{ Reviewer } & \multicolumn{1}{c|}{ Organization } \\
\hline Steering Committee & $7300,7800,7900$, customer organizations \\
\hline DIN Work Team & $7809-1$ \\
\hline & \\
\hline & \\
\hline & \\
\hline & \\
\hline
\end{tabular}

Completed by: R. F. Matthews

Date: $1 / 16 / 96$ 


\section{Pilot Planning Worksheet \#2}

Process Name:_Do-It-Now Building Maintenance

\section{Pilot Indicators:}

What indicators are key in determining whether a change to the process has been successful and how will they be measured?

\begin{tabular}{|l|l|l|}
\hline \multicolumn{1}{|c|}{ Description } & \multicolumn{1}{|c|}{ How Measured? } & Performance Standards. \\
\hline Customer Satisfaction & Customer Feedback Form & $\begin{array}{l}\text { Positive trend compared } \\
\text { with baseline }\end{array}$ \\
\hline $\begin{array}{l}\text { Affect on maintenance } \\
\text { workload }\end{array}$ & $\begin{array}{l}\text { Number of MSRs } \\
\text { processed per time } \\
\text { interval }\end{array}$ & $\begin{array}{l}\text { Negative trend compared } \\
\text { with baseline }\end{array}$ \\
\hline Cost & $\begin{array}{l}\text { Maintenance cost per } \\
\text { square foot }\end{array}$ & $\begin{array}{l}\text { Negative trend compared } \\
\text { with baseline }\end{array}$ \\
\hline & & \\
\hline & & \\
\hline
\end{tabular}
Completed by:
R. F. Matthews
Date: $1 / 16 / 96$ 


\section{Pilot Planning Worksheet \#3A}

Process Name: Do-It-Now Building Maintenance

\section{Part I - Stakeholders}

\section{Agreements}

Steering Committee approved pilot implementation on [Date]

\section{Part II - Team Members}

Reengineering Team approved pilot implementation on [Date]

Completed by: $\underline{R}$. Matthews Date:April 18, 1996 


\section{Pilot Planning Worksheet \#3B}

\section{Agreements}

\section{Part III - Support and Participants}

Location of the Pilot: Labwide at SNL Albuquerque

What are the risks and benefits of conducting the pilot at this location?

The pilot will demonstrate conclusively whether DIN works labwide.

The major risk is that scaling to the whole New Mexico site will require more resources than are available.

Have the following items been clarified to all pilot participants:

What changes have to take place and why? Yes X Date completed:12/18/95

Where changes are taking place? Yes X Date completed_12/18/95

What new skills or perspectives are needed by pilot participants?

Increased emphasis on customer service.

Ability to plan his or her own work

Use of DIN work control and tracking tools

Have the pilot participants been given the opportunity to indicate their concerns and have them addressed?

Yes X Date completed: April 1, 1996

\begin{tabular}{|l|l|}
\hline \multicolumn{1}{|c|}{ Concerns } & \multicolumn{1}{|c|}{ How Addressed } \\
\hline All & $\begin{array}{l}\text { Pilot participants were involved in the } \\
\text { reengineering team as soon as they were } \\
\text { selected and were included in pilot } \\
\text { design discussions. }\end{array}$ \\
\hline & \\
\hline & \\
\hline
\end{tabular}

Completed by: R. Matthews

Date:_April 18, 1996 


\section{Step \#6: Implement the New Process}

\section{Step *6.1 Develop an Implementation Plan}

Confirm the learning from the pilot

Do all stakeholders understand, concur with, and agree.to support the findings of the pilot?

Is there agreement that the environment where the pilot was performed is realistic enough to permit generalization of the results elsewhere?

Is there agreement that the piloted changes will be accepted by people in the process over time?

Develop and Implementation Plan

Develop and communicate the objective(s) of the changes to be made to everyone involved.

Determine what actions are necessary to accomplish the stated goals and who will take the lead responsibility to ensure that each of those actions is accomplished accurately and timely.

What are people required to do differently?

What factors should be present in the workplace to ensure that a change in behavior occurs?

Has a comprehensive control plan been developed and distributed to individuals within the process? 
Have measures been developed (that are a subset of those used during the pilot)? These should be:

Easily obtainable.

Critical to process performance.

Timely.

Accessible to the person who needs the feedback.

Have organizational goals and objectives, business plans, etc. been revised to incorporate changes required by the new process?

Have individual performance objectives been revised to incorporate changes required by the new process?

What education and skills are required by individuals in the process to ensure the success of the changes?

Have appropriate systems been established to provide frequent and relevant feedback to individuals within the process as to how well their jobs are being performed?

\section{Process FMEA}

Has the team, stakeholder(s), customer (s) and sponsor tried to list all the things that could go wrong during the implementation (i.e., potential failure mode) and their potential effects/impacts?

Have they developed preventive or contingency plans (i.e., potential causes, process controls and recommended actions) for each potential failure?

Do individuals in the process know how to handle unusual or non-anticipated situations as they come up in the implementation?

\section{Step \#6.2 Execute the Plan}

Are the sponsor(s) and stakeholder(s) leading the implementation?

To be determined 
Have the customer(s) "signed off" on the improvements?

Yes, through the ad hoc committee of customer representatives. Favorable reception of the pilot can be seen as endorsement by customers as well. 


\section{Appendix 4}

\section{Comparative Analysis Reports}

\section{Lawrence Livermore National Laboratory}

The LLNL approach to team-based maintenance service.is called "windowing." This concept focuses on preventive maintenance (PM), since it was one area customers identified as needing most improvement. Lack of overall focus -. caused customers to get multiple, unscheduled maintenance calls on the same or similar pieces of equipment. This could be a serious problem, since workers showing up to work on roof-mounted equipment, for example, could shut down a whole building. This is because emissions are not allowed when someone is on the roof. As a result, one building was shutting down 88 days per year for maintenance, even though analysis showed there were only 12 days of scheduled maintenance required per year.

Under the windowing system, each building at the Laboratory (with the exception of some small, temporary buildings and MOs) is scheduled for a twoto five-day period, or window, of PM twice a year. Plant Engineering personnel negotiate with representatives of the building occupants to determine the required scope of maintenance services. While the building remains open during the window, occupants know that equipment can be shut down during the window. Thus laboratories tend to be unoccupied, while their occupants do office work, travel, etc. If preventive maintenance workers find deficiencies, they can call on the resources of the central Plant Engineering shops to perform corrective maintenance during the window.

Windows are usually scheduled at the beginning or end of the week so that some work can be accomplished on the weekends. This allows access to the building when it is completely unoccupied for such tasks as spraying for weeds around the building perimeter.

Customer satisfaction with windowing is very high, since maintenance-related down-time has been greatly reduced. In general, craft workers are also enthusiastic about the windowing process. They give several reasons:

- The quality of work has improved due to empowerment and feeling of relevance on the part of the craftspersons.

- Workers have immediate access to craft support for preventive and corrective maintenance

- Building occupants tend to stay out of the way during the window, making maintenance work quicker and easier.

- Workers have advance notice of the type of work to be done and are allowed to do it in the best way they know how.

- Working on a team is a better environment than working alone, 
- Technical support from vendors can be brought in to give on-the-job training or perform special maintenance procedures.

\section{Idaho National Engineering Laboratory.}

INEL employs 8000 people, 6000 of whom work for Lockheed-Martin. They are spread over 890 square miles in several large and small facilities. Of the total, 500 work for the Facilities, Utilities, and Maintenance (FUM) organization, which provides services for the Chemical Processes Plant (CPP), Test Area North (TAN), in-town facilities, and Central Facility Area. Other areas (test reactor facility, radioactive materials) buy crafts work from FUM.

Work structure was a big issue in the latest INEL quality initiative. Crafts workers suggested a new organization, which was accepted. The concept is multi-craft crews assigned to facilities (with flexibility to meet extraordinary demand). Each facility has single point of contact with FUM. The Central Facilities Area has special shops to handle central area and "body shop" support for other areas.

Maintenance requests go to a core team for the program functional area. The core team includes safety, fire protection, radiation protection, industrial. hygiene, quality, engineering, and NEPA support personnel. They are dedicated to reviewing and approving maintenance work orders. A maintenance foreman sits on the core team to give the crafts perspective. The core team likes to use their foreman's team, but they can assign work to any team on priority basis.

Every day, the core teams meet to consider the requests and may request additional information. If the core team decides they have the resources to do it, the request gets a number and goes into the database. If it needs planning, engineering, radiation protection package, etc., it goes to them. When all of the information is in, along with needed permits, the work order is scheduled. The core team sets up required outages, etc. The result of this process is to greatly reduce the amount of time required to get proper approvals and permits for maintenance work at high-rigor facilities.

In addition, INEL has had a team-based system for maintenance of low-rigor buildings called Rapid Maintenance Response (RMR). There were five people on an RMR team, an electrician, mechanic, carpenter, pipe fitter, and laborer (often). For outages, team would rent an electrician from the central program support group pool.

The RMR teams were limited to jobs that took less than 4 hours, and they did not do hazardous work. Therefore, their work was mostly routine maintenance. A dispatcher in each area handled calls. Otherwise, the teams looked through one building a week. 
The teams felt like they owned the buildings they worked on. This encouraged close contact with building occupants. Unfortunately, budget cuts caused INEL to drop the RMR concept and assign the workers to area teams or to the Central Facilities Area shops. 